\title{
INNOVACIÓN EN LAS ORGANIZACIONES Y SERVICIOS PÚBLICOS: ¿EL ESLABÓN PERDIDO? BASES PARA LA TRANSICIÓN HACIA UN MODELO DE INNOVACIÓN
} ABIERTA Y COLABORATIVA

\author{
Álvaro V. Ramírez-Alujas \\ alvaro.ramirez.alujas@gigapp.org \\ Grupo de Investigación en Gobierno, Administración y Políticas Públicas \\ Instituto Universitario de Investigación Ortega y Gasset, Universidad Complutense de Madrid
}

Junto con debatir el concepto, aplicación y desarrollo de la innovación en el sector público, el artículo propone una agenda de transformación de las organizaciones públicas hacia un modelo de gobernanza colaborativa en el marco de las iniciativas de gobierno abierto. Se argumenta que este cambio de paradigma permitiría la configuración de servicios públicos 2.0 que, entendidos como plataformas abiertas para la acción colectiva, promuevan una real y activa participación e involucramiento de los ciudadanos en la gestión estatal.

Palabras Clave: Innovación abierta, gestión pública, gobernanza colaborativa, gobierno abierto. 
INNOVATION IN PUBLIC ORGANIZATIONS AND SERVICES: THE MISSING LINK? A STARTING POINT FOR A TRANSITION TOWARDS OPEN AND COLLABORATIVE INNOVATION

As well as debating the application and development of the concept of innovation in the public sector, the paper proposes an agenda for moving public organizations towards a model of collaborative governance within an open government framework. It is argued that this paradigm would allow for the configuration of public service 2.0 which, understood as open platforms for collective action, would promote a real and active citizen's participation and involvement in public management.

Keywords: Open innovation, public management, collaborative governance, open government. 


\section{INTRODUCCIÓN}

La investigación sobre el fenómeno de la innovación en el gobierno y en las administraciones públicas se ha incrementado de manera sustantiva en los últimos años como nuevo espacio de reflexión y práctica para impulsar procesos de modernización y mejora en la gestión de servicios e instituciones públicas (Moore et al, 1997; Altshuler y Behn, 1997; Osborne y Plastrik, 1997; Borins, 2001; Mulgan y Albury, 2003; Moran, 2004; Osborne y Brown, 2005; Bertucci y Alberti, 2006; Hartley, 2006; Koch y Hauknes, 2006; Verhoest, Verschuere y Bouckaert, 2007; Harris y Albury, 2009; Maddock, 2009; Mulgan, 2009; Potts, 2009; Kohli y Mulgan, 2010; Moore y Hartley, 2010). A ello se suma el interés por desarrollar marcos conceptuales y analíticos que sirvan de base para entender el fenómeno de la innovación ${ }^{1}$, identificar sus variables principales (bajo la lógica de observarlo como un proceso de carácter sistémico) e identificar con claridad sus elementos o componentes a fin de ir configurando y adaptando un modelo de aplicación propia a la naturaleza, intereses y particularidades del sector público (Borins, 2006; Pollitt, 2008; Eggers y Singh, 2009; Bloch, 2010; OECD, 2010; Bason, 2010; Hilgers y Piller, 2011; entre otros).

Todo ello si bien ha contribuido a la conformación de un marco de referencia para analizar este peculiar objeto de estudio, ha evidenciado la pluralidad de enfoques (dispersos) existentes y el carácter polisémico y elusivo que el concepto de innovación trae aparejado al intentar desplegar sus potencialidades en la esfera de los asuntos de gobierno y particularmente, en la gestión pública. La falta de prioridad en la investigación aplicada sobre innovación en el sector público es en parte una consecuencia de una miopía disciplinaria (Windrum, 2008) que se vio influida además, por la vieja visión que asociaba el concepto de innovación al aparato productivo mientras que el sector de servicios era considerado improduc-

\footnotetext{
Algunos autores incluso van más allá en sus argumentos: Las organizaciones de servicio público (OSP) han existido tradicionalmente en un entorno relativamente estable, caracterizado normalmente por un cambio paulatino a pequeña escala y de desarrollo gradual. Sin embargo, la presión conjunta de unos presupuestos más reducidos y una mayor incertidumbre política y económica en los contextos en los que ellas operan ha logrado derribar las certezas convencionales de las operaciones que realizan de manera cotidiana. Ambas fuerzas han marcado una agenda basada en la necesidad de gestionar proactivamente el cambio y la innovación más que en mantener procesos obsoletos o en reaccionar ante imposiciones externas (Osborne y Brown, 2005).
} 
tivo y tecnológicamente retrasado. Dicha mirada ha cambiado profundamente en años recientes con el "explosivo" interés en invertir en investigación y desarrollo en la esfera privada, y por el exponencial repunte y orientación hacia una economía basada en la prestación de servicios.

El presente artículo pretende contribuir a sintetizar los principales enfoques de los que se dispone actualmente para entender el fenómeno de la innovación en el sector público en clave comparada dentro del debate en la literatura especializada sobre el tema e intentar sostener una matriz que dé cuenta del estado del arte en estas materias desde la perspectiva del estudio de las ciencias de la administración y sus derivados. Para ello utilizaremos gran parte de las ideas, síntesis y hallazgos de un estudio previo realizado sobre el tema (Ramírez-Alujas, 2011). Por otro lado, se propondrán y discutirán una serie de ideas sobre el nuevo rumbo que ha venido tomando el debate y la práctica de la innovación pública en los últimos años, donde conceptos tales como "inteligencia colectiva", "innovación abierta", "pensamiento de diseño" y "co-creación" han ido contribuyendo a refrescar las miradas y actualizar la urgente necesidad por integrar el desarrollo y aplicación del concepto de innovación como un elemento central en las estrategias de trabajo de las organizaciones y servicios públicos, y no como una tarea marginal o anexa a las actividades de gobierno y gestión pública.

\section{EL FENÓMENO DE LA INNOVACIÓN EN EL SECTOR PÚBLICO Y LA REFLEXIÓN aCADÉMICA: ¿LAS NUEVAS ROPAS DEL EMPERADOR? Síntesis CONCEPTUAL, BASES PARA UNA APROXIMACIÓN GLOBAL Y PARA LA GENERACIÓN DE UN MARCO DE REFERENCIA APLICABLE AL SECTOR PÚBLICO}

La innovación es un fenómeno complejo, sistémico, que depende de la confluencia de muchos factores y protagonistas, de las relaciones que se dan entre ellos y de las capacidades e infraestructura que en conjunto facilitan el proceso (CNIC, 2010). Si bien son las organizaciones y quienes trabajan en ellas los actores principales de la innovación, se requiere del desarrollo de una comunidad y una dinámica permanente que permita aprovechar los recursos disponibles desde las emergentes nomenclaturas que se comienzan a moldear en lo que se refiere a la sociedad de la información, el Estado Red y los nuevos espacios de aprendizaje y colaboración que son producto de la llamada gestión del conocimiento, del 
trabajo en redes distribuidas y la ventaja que otorga la generación de valor compartido (Porter y Kramer, 2011). En esta perspectiva, es urgente el contribuir a estructurar una combinación virtuosa de factores que faciliten y promuevan la innovación en el interior de los organismos públicos (y más allá). Se requiere de nuevas capacidades y competencias flexibles para usar y adaptar tecnologías, para aprender y desaprender constantemente, para generar y gestionar conocimiento y fluir de manera adecuada frente a los incesantes cambios del mundo en su actual momento de desarrollo y radical transformación hacia una nueva frontera paradigmática.

Generalmente, se asocia el concepto de innovación de manera automática al mundo de la empresa y los negocios, y hoy en día más directamente al ámbito de los avances tecnológicos y el uso intensivo de las nuevas herramientas que circulan en la "Galaxia Internet" (Castells, 2009). Sin embargo y hasta hace unos pocos años atrás, poco o nada de ello se relacionaba con el gobierno y el sector público. Se entendía de facto que las posibilidades de innovar en las Administraciones Públicas era una quimera en la que no valía la pena perder el tiempo ni menos invertir recursos. Ello ha cambiado radicalmente en el inicio del nuevo siglo y su expresión se devela cotidianamente en los debates y en la práctica sobre la oportunidad de mejorar los servicios públicos; incrementar el desarrollo de estrategias de gobierno y/o administración electrónica; impulsar la aplicación de sofisticados dispositivos y modelos de gestión para rediseñar procesos y simplificar procedimientos; diseñar y poner en marcha enfoques de gobierno abierto con énfasis en la apertura, disponibilidad, accesibilidad y reutilización de datos públicos, el fomento de espacios participativos y el uso de redes sociales, lo que se suma a las variadas formas de colaboración masiva y generación de nuevas aplicaciones tecnológicas de carácter ciudadano potenciando el cultivo del capital social y facilitando los procesos de gestión del conocimiento entre los diversos actores.

Lo anterior es reflejo de que algo ha venido cambiando de manera profunda y que, muy probablemente, su ruta de navegación y los nuevos territorios por descubrir será exponencial en los próximos años lo que, bajo una mirada entusiasta, motivará radicales transformaciones en la forma en que entendemos, gestionamos y desarrollamos nuestros sistemas político-administrativos (Ramírez-Alujas, 2010). A menudo la cuestión de la innovación se aborda a través de los conceptos de ideas revolucionarias y tecnologías avanzadas, y del papel de personas rupturis- 
tas y carismáticas (emprendedores). Una gran parte de la literatura está dedicada a corporaciones privadas vanguardistas con altos niveles de flexibilidad y la libertad para perseguir grandes ideas. Solo se menciona a los gobiernos en tanto que estos ahogan la innovación o en relación con las medidas que deberían tomarse para promoverla (Lewis, 2010). Por otro lado y más vinculado a la necesidad de generar una cuerpo conceptual común y el desarrollo de líneas de investigación propias sobre la innovación en el sector público, ha surgido un interesante debate académico que recién comienza a mostrar sus primeros resultados. Un notable ejemplo es el que nos ofrece Christopher Pollitt (2008) al diagnosticar el "estado del arte" que actualmente presenta la cuestión y proporcionar algunas premisas de base que es necesario considerar para avanzar en un programa de investigación sistemático, estructurado y riguroso sobre el tema:

1. La innovación "no es un objeto concreto, se trata de un concepto, o mejor dicho una palabra con las etiquetas de un concepto", en la que no hay un acuerdo común en su definición y existen evidentes dificultades en acunar un significado operacional, y todo ello impacta negativamente en los procesos de obtención, análisis, medición y comparación de información y/o casos ${ }^{2}$;

2. La innovación no es "sólo" un concepto, es actualmente un concepto muy de moda, con un tono normativo muy positivo. Lo encontramos perpetuamente en los labios de los políticos y los gurús de la gestión;

3. La innovación en el sector público no es nada nuevo. Al mirar la historia observamos con claridad que han existido desde siempre notables innovaciones en el sector público, sólo que no las llamamos así.

4. Hay que descartar la suposición común de que la innovación es algo que sucede principal o exclusivamente en el sector privado, y que por lo tanto, necesariamente se tiene que ir allí para encontrar la manera de llevarla a cabo.

5. La innovación es un negocio arriesgado. Supone asumir riesgos bien gestionados y sustentar consecuencias no deseadas o imprevistas, incluso puede no provocar las mejoras (esperadas) en los servicios públicos.

2 Con todo, podemos afirmar que la innovación es al mismo tiempo un proceso ("innovación”) como un resultado de ese proceso ("una innovación"). 
Es así, que una importante cuestión para intentar desarrollar un marco de referencia alude a cómo se define la innovación en el contexto del sector público. Dicho debate ha sido, al menos, controversial y difuso en contraste con los avances que en la materia se han impulsado en el sector privado. En el actual momento, se afirma que el factor clave para el crecimiento de la productividad en la economía en red basada en el conocimiento es la innovación: la capacidad para recombinar factores de producción de una forma más eficiente y/u obtener un valor añadido mayor en el proceso o el producto (Castells, 2009). Ello contrasta con la definición utilizada en el Manual de Oslo donde se planteaba que la innovación radica en "la aplicación de una nueva o significativa mejora en un producto (bien y/o servicio) o proceso, un nuevo método de comercialización, o un nuevo método de organización en las prácticas de negocio, lugar de trabajo o en las relaciones externas" (OECD, 2009). Conviene entonces contrastar dichas definiciones con las que se han venido ensayando para incorporar la innovación en el sector público (Cuadro 1). 


\section{Cuadro 1. ¿Qué se entiende por innovación en referencia al sector público?}

Moore et al, $\quad$ Definen la innovación en términos de novedad y el grado de cambio en (1997) relación con la organización: "Una innovación es cualquier cambio razonablemente significativo en la forma en que una organización opera, se administra o define su misión básica”.

Mulgan y

Albury (2003)

Osborne y Brown
$(2005)$

Hartley (2006)
Son "nuevas ideas que funcionan", para luego precisar que: "La innovación exitosa es la creación e implementación de nuevos procesos, productos, servicios y métodos de entrega que dan lugar y se traducen en mejoras significativas en los resultados de eficiencia, eficacia y calidad".

La innovación es un proceso diferente a la invención y consiste en la aplicación y/o adaptación de nuevos conocimientos: Hay tres elementos implicados: los actores (innovadores), el proceso (la innovación) y los resultados (innovaciones). El elemento central que distingue la innovación del cambio incremental es el impacto del proceso de cambio en la discontinuidad con el paradigma predominante de organización, producto/servicio o mercado.

Son nuevas ideas que se aplican, que por lo general son lo suficientemente duraderas como para afectar de manera apreciable el carácter o las operaciones de la organización (y por tanto son mucho más que mejoramiento continuo), que son reconocidas como tales por las actores clave interesados y que no necesariamente son exitosas.

\begin{tabular}{ll}
\hline $\left.\begin{array}{l}\text { Proyecto Publin } \\
\text { (Koch y Hauknes, }\end{array} 2006\right)$ & $\begin{array}{l}\text { La innovación en el sector público radica en "hacer algo diferente y delibe- } \\
\text { radamente con el fin de lograr ciertos objetivos o bien, cambios deliberados } \\
\text { en el repertorio de acciones o comportamientos con un objetivo específico } \\
\text { en mente". }\end{array}$ \\
\hline $\begin{array}{l}\text { National Audit } \\
\text { Office - NAO }\end{array}$ & $\begin{array}{l}\text { La innovación es tener ideas nuevas, desarrollando las mejores y aplicándo- } \\
\text { las de tal manera que hay (al menos) una buena probabilidad de que van a } \\
\text { mejorar los métodos con los que opera la organización y/o realiza sus acti- } \\
\text { vidades. Las nuevas ideas sin algún grado de aplicación no son suficientes. }\end{array}$ \\
\hline $\begin{array}{l}\text { CEPREDE } \\
(2006)\end{array}$ & $\begin{array}{l}\text { La innovación en el sector público, "debería ser definida en un sentido más } \\
\text { amplio, como todo proceso de generación y aplicación de nuevas ideas } \\
\text { capaces de mejorar la operatividad de las instituciones y elevar el nivel de } \\
\text { vida de una sociedad". }\end{array}$ \\
\hline $\begin{array}{l}\text { Audit Comission } \\
(2007)\end{array}$ & $\begin{array}{l}\text { Son las prácticas realizadas por las organizaciones con el fin de mejorar el } \\
\text { producto o servicio que prestan, caracterizado por: } \\
\text { - Cambio - cambio radical e impacto } \\
\text { - Novedad - es algo nuevo para la organización en cuestión } \\
\text { - Acción - supone llevarlas a cabo, no sólo es una "buena idea" }\end{array}$ \\
\hline
\end{tabular}




\begin{tabular}{l|l}
\hline $\begin{array}{l}\text { Geoff Mulgan } \\
(2007)\end{array}$ & $\begin{array}{l}\text { La definición más simple es que la innovación en el sector público apela a } \\
\text { que las nuevas ideas funcionen en la creación de valor público. Las ideas } \\
\text { tienen que ser, por lo menos en parte, nuevas (en lugar de sólo mejoras), } \\
\text { tomadas en cuenta (en lugar de ser sólo buenas ideas) y útiles. Esta defi- } \\
\text { nición por lo tanto, requiere que las innovaciones deben ser nuevas, estar } \\
\text { implementadas y tener un impacto positivo en la creación de valor público. }\end{array}$ \\
\hline $\begin{array}{l}\text { Currie et al, Sobre } \\
\text { el concepto de } \\
\text { innovativeness } \\
\text { (2008) }\end{array}$ & $\begin{array}{l}\text { Supone "la búsqueda de soluciones creativas, inusuales o nuevas a los pro- } \\
\text { blemas y necesidades, incluyendo nuevos servicios y formas de organiza- } \\
\text { ción y mejora de los procesos". }\end{array}$ \\
\hline $\begin{array}{l}\text { Australian Natio- } \\
\text { nal Audit Office - } \\
\text { ANAO (2009) }\end{array}$ & $\begin{array}{l}\text { "La innovación es la aplicación de nuevas ideas para producir mejores re- } \\
\text { sultados". }\end{array}$ \\
\hline $\begin{array}{l}\text { Christian Bason } \\
\text { (2010) }\end{array}$ & $\begin{array}{l}\text { Es el proceso de crear una nueva idea y transformarla en valor para la so- } \\
\text { ciedad (valor público). }\end{array}$ \\
\hline $\begin{array}{l}\text { Department of } \\
\text { Business, Innova- } \\
\text { tion and Skills - } \\
\text { BIS, UK (2010) }\end{array}$ & $\begin{array}{l}\text { La innovación es el proceso de identificación, verificación, aplicación y } \\
\text { difusión de ideas que agreguen valor. }\end{array}$ \\
\hline
\end{tabular}

Elaboración propia en base a Ramírez-Alujas (2010, 2011).

Más recientemente, la National Audit Office (NAO) del Gobierno de Australia llevó a cabo una Encuesta Transversal sobre innovación en el Gobierno Central (NAO, 2009). Lo interesante de este estudio es que si bien no explicita una definición de innovación, tiene la peculiaridad de permitir que sean los mismos encuestados quienes al responder las preguntas de cómo conceptualizar las innovaciones en sus organismos, configuren una aproximación desde la práctica cotidiana al tema. Entre los tópicos en los que existen acuerdos sustantivos por los encuestados encontramos las siguientes afirmaciones:

- La innovación es adoptar exitosamente las prácticas de otras organizaciones

- La innovación es ser los primeros en hacer algo

- La innovación y la creatividad son la misma cosa

- La innovación se trata de resolver problemas

- No todas las organizaciones pueden ser innovadoras

- No todas las organizaciones deberían ser innovadoras

- Para que algo sea innovador debe ser exitoso

- La innovación debe agregar valor 
Por tanto, la innovación es un término elástico que necesita ser entendido como una práctica de actores reales con sus disposiciones y preferencias específicas (Lewis, 2010). Sobre dicha base, se llevó a cabo un proyecto a gran escala en once municipios del Estado de Victoria (Australia), dirigido a examinar internamente la innovación (Considine y Lewis, 2007). El objetivo del estudio era descubrir las orientaciones de la innovación y su relación con las estructuras formales e informales, así como su impacto relativo en la innovación gubernamental. En particular, intentaba establecer relaciones respecto a funciones, cargos y redes de contactos. Se distinguieron cinco nociones diferentes de innovación que pueden resumirse como sigue:

\begin{tabular}{l|l} 
Institucional & La innovación depende de factores organizacionales. \\
\hline Estructural & La innovación tiene que ver con grandes cambios externos. \\
\hline Escéptico & No se sabe si el gobierno desempeña un papel en la innovación. \\
\hline Incremental & La innovación se basa en mejoras pequeńas y planificadas. \\
\hline Adaptativo & Innovación significa adaptarse a cosas de otros sitios. \\
\hline
\end{tabular}

Fuente: Adaptado de Considine y Lewis (2007).

Particularmente, se destaca el hecho de que el trabajo con redes de contacto informales contribuye directamente a explicar la innovación: Aunque la centralidad dentro de las redes de contactos está relacionada con la antigüedad jerárquica y no es posible evaluar la contribución por separado de estas dos variables, nuestros descubrimientos encajan con la idea de que los innovadores son expertos en trabajar a través de relaciones externas a las estructuras formales con el fin de conseguir resultados (Lewis, 2010). Por otro lado, el estudio demostró que las redes de contactos aportan más información sobre la innovación que cualquier otro factor.

Finalmente y para complementar la mirada anterior, los elementos clave en la definición de la innovación en el sector público apelarían a (Bloch, 2010): a) la implementación (la innovación es acerca de buenas ideas pero ello no es condición suficiente, se requiere aplicarlas); b) éxito (más allá de la aplicación de una idea es necesario que genere un impacto positivo o contribuya a la creación de valor público, aun cuando ello sea más difícil de medir dada la multiplicidad de objetivos y los horizontes temporales presentes en los dominios de la gestión pública); c) grado de cambio necesario (se refiere a la medición del impacto de los 
cambios impulsados - muchas veces la innovación afecta directamente a quien(es) la implementa(n) - y a distinguir entre los cambios derivados de la innovación frente a los cambios menores que forman parte de las operaciones diarias, o tienen lugar de forma continua); y d) fuentes de la innovación (considerar la principal cuestión de si los cambios de mandato político -que no son el resultado de las decisiones tomadas por la propia organización- afectan y/o pueden influir en las innovaciones, sus resultados y efectos).

\section{¿POR Qué INNOVAR EN El SECTOR PÚBLICO?:}

\section{LO ESENCIAL EN EL CORAZÓN DE LO IMPORTANTE}

Una mirada transversal al intento por justificar la importancia de la innovación en el sector público nos muestra el peso que puede llegar a tener trabajar seriamente en su conceptualización y desarrollo (Mulgan, 2009). Si bien se trata de un debate abierto, conviene disponer de una síntesis que aglutine las ideas fuerza que se han esgrimido a favor de configurar un espacio preferente de estudio, sistematización y aplicación práctica de la innovación en la esfera gubernamental y en las administraciones públicas que, de paso, dé cuenta del valor que agrega al incorporarla como elemento catalizador en los esfuerzos por modernizar y mejorar las prestaciones y servicios públicos así como también, contribuir al fortalecimiento de la gobernanza y el buen gobierno (Cuadro 2). 


\section{Cuadro 2. Razones para innovar en el sector público}

\begin{tabular}{c|c} 
Mulgan y & a) Para responder más eficazmente a los cambios de las necesidades públicas \\
y las crecientes expectativas ciudadanas (sobre todo hoy en día, para supe- \\
rar el obsoleto enfoque fordista de "una talla única válida para todos" y la \\
exigencia por un trato más personalizado y adaptado a las necesidades de \\
los usuarios); \\
b) Para contener los costes y aumentar la eficiencia, especialmente en contex- \\
tos de restricciones presupuestarias y políticas de austeridad fiscal; \\
c) Para mejorar la prestación y los resultados de los servicios públicos, espe- \\
cialmente para atender las áreas donde las pasadas políticas públicas han \\
hecho pocos progresos o, sencillamente, han fracasado en sus resultados \\
esperados e impacto; y \\
d) Para aprovechar todo el potencial de las Tecnologías de Información y \\
Comunicación (TIC).
\end{tabular}

Fuente: Elaboración propia sobre la base de Ramírez-Alujas (2010, 2011). 


\section{TIPOS DE INNOVACIÓN: EL MAPA NO ES EL TERRITORIO}

Actualmente, se dispone de una abrumadora evidencia -manifestada en diversos programas y políticas públicas en materia de salud, educación y vivienda, por ejemplo- de que estamos tratando de resolver los problemas emergentes de nuestras sociedades desde estructuras, modelos y procesos que fueron diseñados para responder a las necesidades del siglo pasado. Si existe un ámbito donde la innovación no ha tenido la presencia esperada es justamente en éste: seguimos tratando de hacer lo mismo esperando resultados diferentes, se sigue operando sobre la base de paradigmas que ya no cuentan con un soporte en la práctica y se mantiene la esperanza de que a través de la lógica incremental podremos enfrentar exitosamente las nuevas realidades. En definitiva, los gobiernos y sus aparatos administrativos siguen haciendo eficientemente lo incorrecto, fenómeno que ha quedado al descubierto al intentar surfear la crisis económica de manera razonable, adecuada y tratando de salir decorosamente de ella (ejemplos de ello sobran pero mencionemos el caso de España, Grecia e Irlanda en el territorio europeo).

$\mathrm{Al}$ respecto, una interrogante fundamental es: ¿Qué tipos de innovación deberían ser considerados como tales en el contexto del sector público? (Bloch, 2010). En la literatura existe un amplio abanico de posibilidades para responder a esta pregunta y un debate heterogéneo y centrífugo sobre la utilidad de uno u otro enfoque. Conviene señalar aquellos que mejor aporte suponen a nuestro esfuerzo de sistematización global (Cuadro 3). 


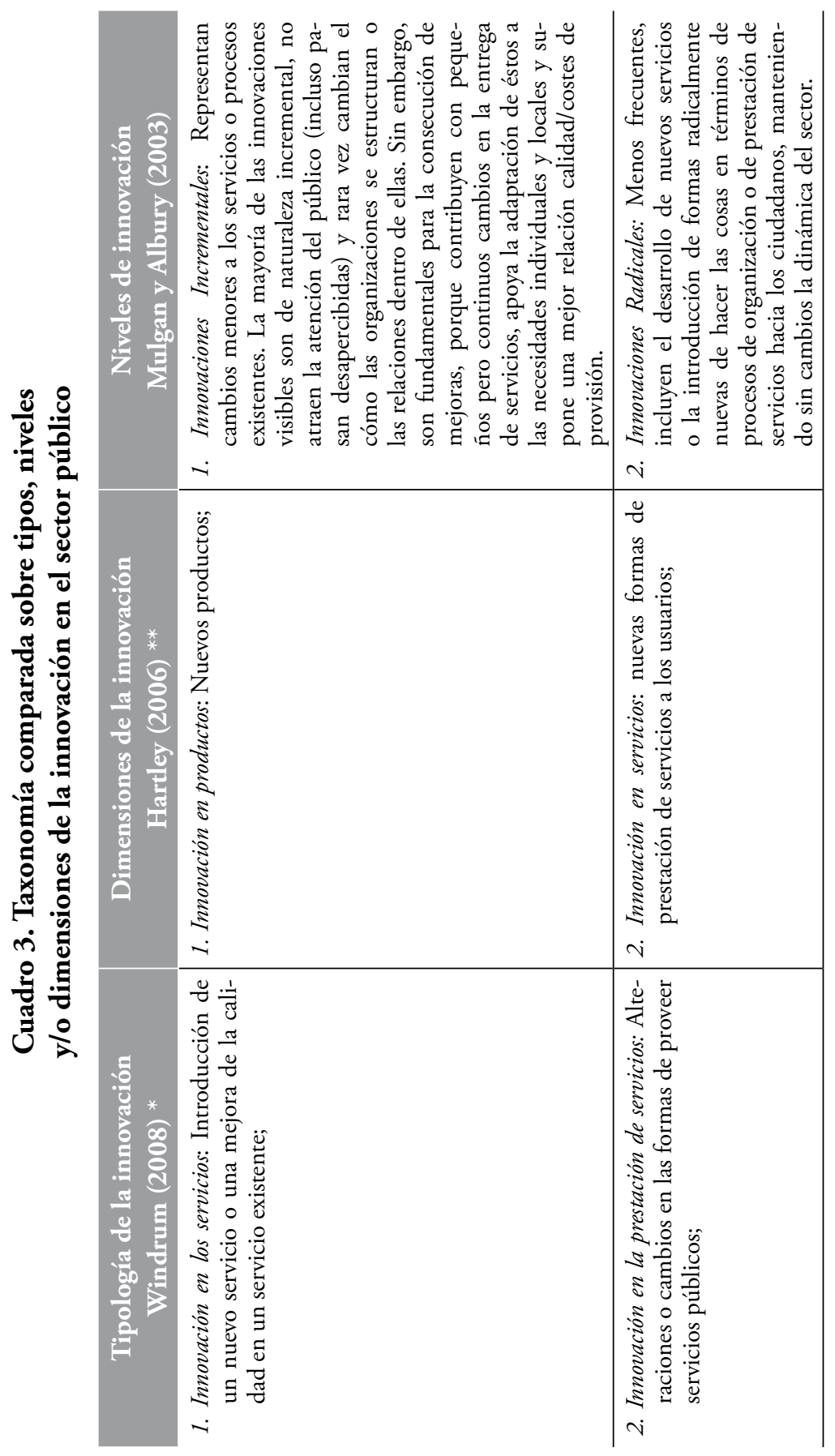




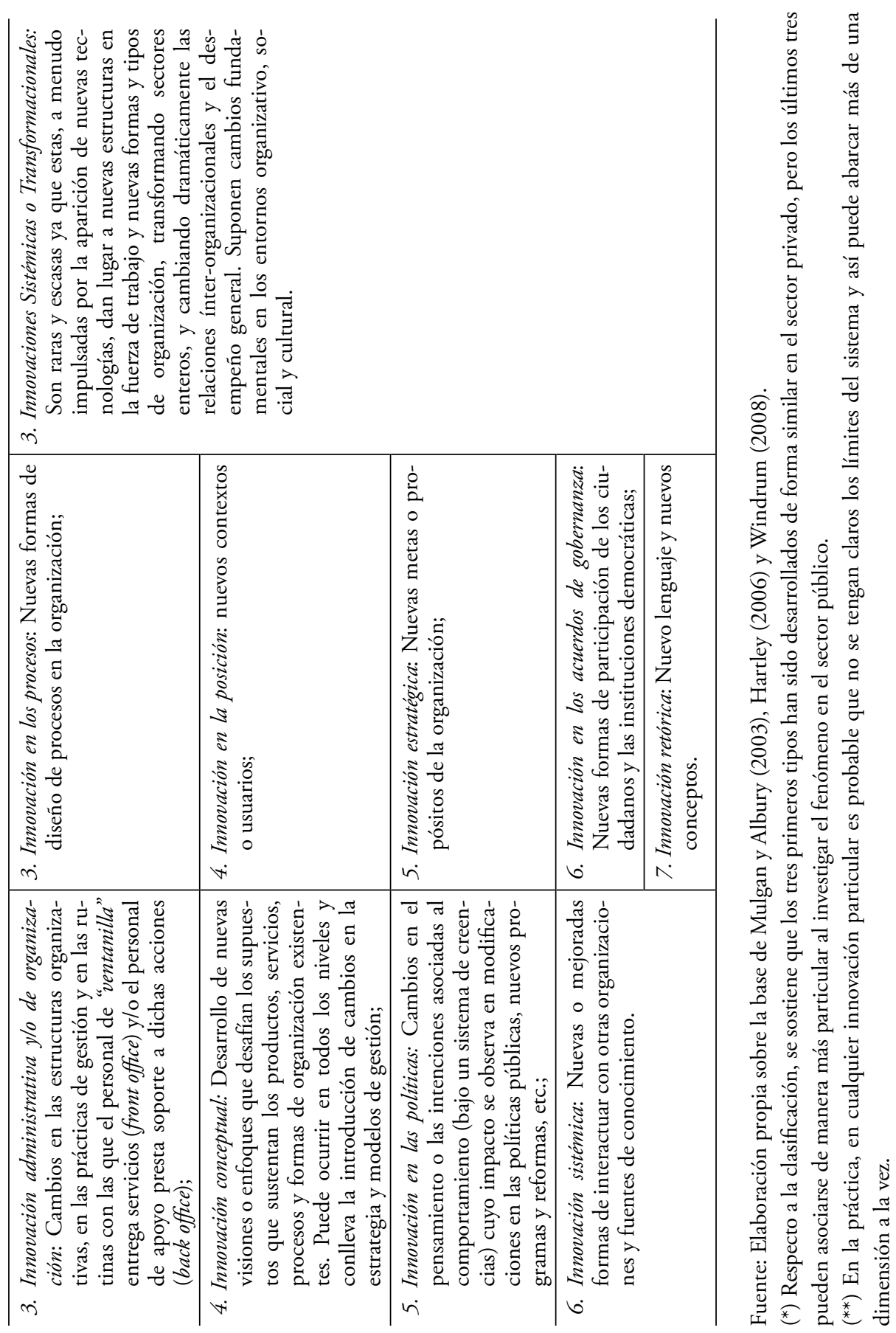


Tomando los interesantes resultados del estudio desarrollado por el Proyecto PUBLIN (2006) que generó una mirada comparada y transversal sobre la situación de la innovación en las Administraciones Públicas de la Unión Europea, podemos esbozar una síntesis global que contraste los principales obstáculos por un lado, y los factores que facilitan y promueven la innovación en el sector público, por el otro (Cuadro 4).

\section{Cuadro 4. Innovación en el sector público: Las dos caras de la moneda}

\begin{tabular}{|c|c|}
\hline Obstáculos y barreras & Promotores y facilitadores \\
\hline $\begin{array}{l}\text { 1. Tamańo y complejidad. El sector público está confor- } \\
\text { mado por entidades muy complejas y a gran escala } \\
\text { desde el punto de vista organizativo. }\end{array}$ & $\begin{array}{l}\text { 1. Foco en la orientación a resolver problemas. Las per- } \\
\text { sonas innovan para resolver ciertos problemas (es- } \\
\text { pecíficos y acotados) mediante cambios radicales. }\end{array}$ \\
\hline $\begin{array}{l}\text { 2. Herencia y legado. Las organizaciones del sector pú- } \\
\text { blico son propensas a las prácticas y procedimientos } \\
\text { arraigados. La mantención del statu quo es la norma, } \\
\text { no la excepción: "Si funciona, no lo toques". }\end{array}$ & $\begin{array}{l}\text { 2. Foco en la orientación a no resolver problemas. } \\
\text { Las innovaciones suponen mejorar (paso a paso) } \\
\text { las dificultades (lógica incremental; mejora con- } \\
\text { tinua). }\end{array}$ \\
\hline $\begin{array}{l}\text { 3. Resistencia de los funcionarios. Hay grupos de jefa- } \\
\text { turas, profesionales o funcionarios públicos con sus } \\
\text { propias comunidades de práctica, sus propios sistemas } \\
\text { de creencias y perspectivas (el dilema de la cultura or- } \\
\text { ganizativa). }\end{array}$ & $\begin{array}{l}\text { 3. Impulso político. El cambio estratégico requiere } \\
\text { con frecuencia de un fuerte apoyo y voluntad po- } \\
\text { lítica (desde arriba hacia abajo). }\end{array}$ \\
\hline $\begin{array}{l}\text { 4. La aversión al riesgo. Los organismos públicos están } \\
\text { bajo la estrecha vigilancia de los políticos y los medios } \\
\text { de comunicación, y los empleados no suelen ser re- } \\
\text { compensados por asumir riesgos ni existen los incenti- } \\
\text { vos para hacer las cosas de otra manera. }\end{array}$ & $\begin{array}{l}\text { 4. Crecimiento de una cultura de análisis crítico/ } \\
\text { evaluación. Las prácticas de evaluación pueden } \\
\text { estimular la innovación. }\end{array}$ \\
\hline $\begin{array}{l}\text { 5. Necesidad de realizar consultas y objetivos (resultados) } \\
\text { poco claros. La amplia gama de actores involucrados y } \\
\text { los intereses en juego, generan presiones variadas. De } \\
\text { manera complementaria, en no pocas ocasiones los re- } \\
\text { sultados del proceso no están del todo claros. }\end{array}$ & $\begin{array}{l}\text { 5. Los mecanismos de apoyo a la innovación. Las } \\
\text { autoridades pueden aplicar medidas de política } \\
\text { destinadas a la financiación y al fomento de la } \\
\text { innovación. }\end{array}$ \\
\hline $\begin{array}{l}\text { 6. Ritmo y la magnitud del cambio. Ha habido tantas } \\
\text { reformas (exitosas, fracasadas e inconclusas) que los } \\
\text { empleados públicos han pasado a "estar cansados o } \\
\text { fatigados de la innovación" (innovation fatigued). }\end{array}$ & $\begin{array}{l}\text { 6. Capacidad de innovación. Los empleados públi- } \\
\text { cos tienen a menudo un alto nivel de competencia } \\
\text { profesional, creatividad y habilidad para la resolu- } \\
\text { ción de problemas. }\end{array}$ \\
\hline $\begin{array}{l}\text { 7. Ausencia de capacidad para el aprendizaje organiza- } \\
\text { cional. }\end{array}$ & $\begin{array}{l}\text { 7. Los factores/promotores de la competencia. Los } \\
\text { objetivos de rendimiento o de mejora de los resul- } \\
\text { tados pueden fomentar el uso de enfoques inno- } \\
\text { vadores. }\end{array}$ \\
\hline $\begin{array}{l}\text { 8. La resistencia de la ciudadanía (opinión pública) a los } \\
\text { cambios e innovaciones. }\end{array}$ & $\begin{array}{l}\text { 8. Los factores tecnológicos. La innovación tecnoló- } \\
\text { gica puede ser un factor determinante para inno- } \\
\text { vaciones posteriores. }\end{array}$ \\
\hline $\begin{array}{l}\text { 9. Ausencia de recursos: financieros; de conocimiento y } \\
\text { capacidad o de soporte y apoyo a las iniciativas. }\end{array}$ & \multirow{2}{*}{$\begin{array}{l}\text { 9. Las ONG y empresas privadas. Los modelos desa- } \\
\text { rrollados por organizaciones no gubernamentales } \\
\text { (ONG) y empresas privadas pueden ser adopta- } \\
\text { dos por las instituciones públicas. }\end{array}$} \\
\hline 10. Obstáculos técnicos. & \\
\hline
\end{tabular}

Fuente: Elaboración propia adaptada a partir del Proyecto Publin (2006). 


\section{a) El vaso medio vacío...}

En la literatura y en los diversos estudios empíricos disponibles (Borins, 2006; Publin, 2006; Considine y Lewis, 2007; entre otros) se han identificado con claridad las potenciales barreras u obstáculos que enfrenta la promoción y desarrollo de la innovación en el sector público. En la mayoría de los casos, se proporcionan una serie de variables (algunas más conceptuales, otras extraídas desde la experiencia concreta) que explican las insuficiencias que operan para adecuar la innovación, incorporarla como práctica permanente y sostener flujos dinámicos que sustenten su validez, reconocimiento y utilidad en el mejoramiento de los servicios y organismos públicos. Todo lo anterior bajo la mirada que pone acento en las particularidades del sector público: espacio que contiene un conjunto de entidades organizativas extremadamente complejas y (generalmente) de gran tamaño, compuestas de sistemas entrelazados de múltiples niveles. Veamos brevemente los principales hallazgos en esta materia.

Mulgan y Albury (2003) identifican una serie de factores que pueden actuar para frenar la innovación en el sector público. Entre ellos se encuentran: la aversión al riesgo, las presiones de entrega y las cargas administrativas (es decir, sin tiempo para pensar en la innovación), la poca capacidad de gestión de riesgos, los horizontes de corto plazo y los presupuestos, la renuencia a cerrar los programas o en su defecto las organizaciones, lo que obstaculiza los acuerdos culturales o de organización, la falta de incentivos, la excesiva dependencia de alto rendimiento como fuente de innovación. Más recientemente, se agregaban algunas "malas razones para evitar buenas innovaciones" (Mulgan, 2009):

- No es trabajo de nadie: Son pocas las organizaciones en el sector público que tienen un responsable de la innovación. Como contraste, una vasta burocracia ha crecido en torno al rendimiento de la gestión, inspección y auditoría;

- Demasiadas reglas: Las burocracias modernas fueron diseñadas para detener las acciones caprichosas e impredecibles. Ello se hace mediante la imposición de normas: la sistematización, la formalización, especificando cómo las cosas deben hacerse y garantizando la uniformidad; 
- Resultados inciertos: La innovación supone riesgos y probar cosas nuevas sin poder garantizar ex ante el resultado final. El dilema de lo nuevo (como los cambios de paradigmas o probar nuevos estilos de hacer las cosas) versus lo ya establecido, que ha dado resultado en el pasado o que al menos no rompe con las sagradas rutinas existentes;

- Altos muros divisorios o la "Torre de Babel" en las burocracias públicas (e insularidad): El sector público tiende a estructurarse en silos separados con "altos muros" divisorios que se replican y reproducen organizacionalmente: entre servicios, departamentos, organismos y hasta cuerpos profesionales. Ello no contribuye a generar espacios de genuina colaboración y proyectos transversales innovadores;

- Estructuras e incentivos inadecuados: Los sectores monopolistas (como el Estado) no suelen ser muy innovadores por la obvia razón de que el monopolista tiene pocos incentivos para invertir los beneficios en nuevos productos y servicios.

Por otro lado, Clark et al. (2008) sugieren el examen de las siguientes barreras: la cultura burocrática, la aversión al riesgo, las prácticas arraigadas y los procedimientos, problemas de disponibilidad para hacer frente a las reformas a gran escala, la falta de capacidad para el aprendizaje organizacional. Un estudio de la NAO (2006) sugiere lo siguiente: la resistencia a nuevas formas de trabajo; diferentes intereses de las partes y actores interesados (stakeholders); conseguir recursos; la fragmentación; la coordinación de los actores; la falta de acuerdo sobre los objetivos; los riesgos de auditoría; la incertidumbre política; la falta de líderes; la falta de capacitación; el trabajo con contratistas. Borins (2006) distingue entre obstáculos que emanan del entorno político (los reglamentos y las leyes; la falta de financiación y la ausencia de una visión clara o de apoyo político); los que surgen desde dentro de la burocracia (la preocupación por la pérdida del control y responsabilidad; pugnas por definir territorios de competencia e influencia; la precaria cooperación tanto interna como externa -entre los actores involucradosy las dificultades de coordinación intergubernamental; los problemas de integrar las nuevas tecnologías; la oposición de los sindicatos o la resistencia de mandos medios); y los que existen en el entorno (la oposición -de la opinión- pública; la oposición de las empresas del sector privado y/o de los afectados; el escepticismo de los ciudadanos). 
Finalmente, la investigación empírica ha planteado la cuestión de los conflictos entre los emprendedores políticos y los emprendedores de servicio. En parte, estos conflictos reflejan los diferentes puntos de vista y perspectivas de las personas que operan en los diferentes niveles jerárquicos. Los estudios de caso indican que los emprendedores políticos están dispuestos a promover una mayor eficiencia, a través de la reestructuración organizativa, al mismo tiempo de elevar estándares a través de la herramientas adscritas a la corriente de la NGP. Los emprendedores de servicio tienden a centrarse en las innovaciones de nivel de prestaciones que mejoran la calidad del servicio, teniendo en cuenta la eficiencia(Windrum, 2008:231). Adicionalmente, se puede afirmar que dado los incentivos existentes y las asimetrías de información presentes en la relación de ambos tipos de emprendedores, ello constituye en sí un problema de agente-principal, largamente debatido en la literatura sobre institucionalismo económico.

\section{b) El vaso medio lleno...}

Los factores promotores de la innovación pública -o variables clave que la impulsan- han recibido una atención considerable en la literatura y en el análisis empírico. Casi todos los estudios existentes sobre innovación en el sector público, en particular los basados en algún tipo de encuesta, dedican un espacio considerable a dichos factores donde se puede constatar que es uno de los ejes de preocupación preferente. El estudio de la NAO (2006) considera una larga lista de factores promotores (desencadenantes): Las necesidades de eficiencia; las nuevas prioridades de los gobiernos; la respuesta a la crisis; el cambio en las prioridades ministeriales; las nuevas tecnologías; el trabajo con organizaciones similares; el cambio en el entorno político; los cambios en el uso de recursos; la aplicación de políticas (en particular para el contexto de la Unión Europea); el cambio de funciones; el sector privado; la acción directa de los ciudadanos/campańas/movilizaciones sociales; spin-offs o proyectos derivados que nacen como extensión de otros trabajos e iniciativas llevadas a cabo.

Para Borins (2006), quien es una de las voces autorizadas más reconocidas y reputadas en el estudio de la temática, y quien ha indagado de manera sistemática el fenómeno de la innovación desde la perspectiva del perfil de líderes y/o emprendedores públicos y de las características de programas destacados por su 
innovación a través de diversos estudios comparados, ha encontrado abundante evidencia sobre los elementos que permitirían potenciar la innovación en el sector público. A su enfoque se le conoce como "Bloques de construcción para la innovación en el sector público" y se resume en cinco aspectos fundamentales:

1. Uso del enfoque de sistemas

2. Uso de las nuevas tecnologías de información

3. Mejora de procesos

4. Participación del sector privado y/o voluntariado (o Tercer Sector)

5. Empoderamiento de las comunidades, usuarios/ciudadanos o funcionarios públicos

\section{Un PUENTE ENTRE dos Miradas [LA PAUSA NECESARIa]: TRANSitando HACIA UN MODELO DE INNOVACIÓN PÚBLICA BASADO EN LA APERTURA, LA PARTICIPACIÓN Y LA COLABORACIÓN}

En la idea de promover la colaboración como un motor y eje dinamizador de los procesos de mejoramiento e innovación en la gestión pública, Alfons Cornella (2012) nos ofrece interesantes argumentos sobre la importancia del tema aplicado al concepto de "Ciudades Inteligentes" (Smart Cities): El futuro es una ciudad donde exista la colaboración en dos sentidos: una ciudad inteligente desde los sistemas y colaborativa desde la gente; una ciudad donde ocurran miles de intersecciones entre empresas y entre individuos; ciudades donde se cree economía desde la intersección de productos y servicios, y donde se resuelvan los problemas desde la intersección de los emprendedores sociales. Una ciudad que no sea capaz de conectar a sus agentes es una ciudad que va a morir, que va a ser absolutamente estéril porque la economía del futuro es una economía de la colaboración: Necesitamos urgentemente un nuevo discurso de ciudad en el que en lugar de hablar de las capas de infraestructura y tecnología, se hable de cómo se crean las condiciones para que los agentes se combinen de forma eficiente para generar nueva economía ${ }^{3}$.

3 Fuente: http://www.co-society.com/es/2012/02/hacia-las-co-ciudades/ 
Un marco que puede ser de utilidad para circunscribir el estado actual de la innovación es el que nos ofrece el siguiente decálogo, bastante a la medida de lo que ha venido sucediendo en los últimos años y que planteado en términos eje y/o dicotomías, permite disponer de una mirada sinóptica sobre el asunto que vale la pena tener presente (adaptado de Cornella, y Flores, 2007):

1. Hibridación: Acción de crear nuevos productos o servicios innovadores a partir de la combinación de otros ya existentes (punto de conexión entre extremos que permite coger lo mejor de cada sector para crear un producto o servicio nuevo). Aplicarlo a las personas o procesos es una de las fórmulas más claras para innovar.

2. Autenticidad/Honestidad: Lo que, de manera explícita o implícita, apela a todo aquello que es anterior a la era industrial y consumista (lo artesano, lo natural, lo ecológico...). Otra acepción del término se refiere a lo genuino y original frente a la misma (no confundir con la expresión inglesa be cool). Es una macrotendencia en alza que además supone el hecho de ser transparente, es decir, sin trampas.

3. Teamdividualism: Neologismo de evidentes raíces anglosajonas para designar una nueva forma de estructurar los procesos de innovación en las organizaciones a partir de grandes individualidades con espiritu de trabajo en equipo. Designa un nuevo modelo de estructura colaborativa del ámbito de las organizaciones, que supone una de las estrategias más claramente enfocadas a la innovación y enaza dos aspectos centrales en este proceso: inspiración y transpiración.

4. Territorialidad/Frontera: Espacio en una organización o espacio geográfico, mental o virtual (Internet) donde se desarrolla la innovación. La frontera determina los nuevos territorios por conquistar y apela a la necesidad de gestionar adecuadamente la creatividad.

5. Efímero/Efervescente: Aquellos productos o servicios innovadores, pero sin visos de continuidad, concebidos para su uso fugaz y enfocados a los hábitos de mercado consumistas. En algunos casos, son antónimos claramente de la Autenticidad/Honestidad. También implicaría el camino trazado desde la complejidad a la simpleza en el diseño y creación de soluciones adaptadas a las propias necesidades de los usuarios y sus peculiaridades (customización).

6. Capilaridad: Cualidad de las organizaciones para que la información fluya entre sus miembros (y más allá), a todos los niveles y en todas las direcciones, con el fin de innovar (desde una mirada transversal y configurada más en la idea de redarquía, en reemplazo de las tradicionales cadenas de mando, autoridad y jerarquía). Puede darse de forma inter- 
na; entre departamentos; en cuanto a la relación con el consumidor; a nivel de redes; etc. Por tanto, los sistemas o redes capilares sirven para permitir que el conocimiento fluya libremente en todas direcciones como remedio contra el síndrome de la peligrosa autosatisfacción endogámica llamada inercia en las organizaciones. En tal sentido, la idea de trabajo en red es consustancial a la capilaridad y se opone al trabajo en silos aislados, fragmentados e insulares (sobre todo entre unidades de una misma figura organizativa)

7. Catálisis: Factor o conjunto de factores que hacen posible la convergencia de elementos necesaria para que se produzca la innovación (una suerte de síntesis de elementos que se conjugan en el lugar preciso, bajo condiciones particularmente favorables y en el momento adecuado).

8. Fracaso: Error o errores controlados (experiencias necesarias) que previenen contra el fracaso total y son, la mayoría de las veces, el paso previo y obligado al éxito de la innovación. En este punto los espacios para generar y probar prototipos (para intentar demostrar que una nueva idea se puede aplicar en la práctica) es fundamental, lo que va de la mano con los umbrales de tolerancia, tanto al fracaso como al riesgo que, generalmente, van ligados (como refleja la conocida expresión utilizada en el MediaLab del MIT: "Demo or die").

9. Radicalidad: Innovación que se adelanta a su tiempo y que marca nuevas categorías sobre las que todos los demás trabajarán a partir de entonces (dicho de otra manera, ser radical supondría marcar una tendencia y trazar un horizonte nuevo que de algún modo cambia las reglas del juego conocidas y las reemplaza por un nuevo modelo y/o paradigma de negocio transformando el mercado y la sociedad).

10. Innovadores: Aquellas personas que tienen la intuición, la energía y el talento para ver más allá e innovar; no hay innovación sin innovadores (y que en el escenario del sector público contrastaría con la propia naturaleza de los gremios y de algunos tipos de funcionarios que tienden a ser conservadores o inmovilistas, en muchas ocasiones anclados en su propio proteccionismo y en la lucha cotidiana por hacer perdurar el statu quo).

Tomando estas ideas como antesala, propondremos en la siguiente sección una breve síntesis de los enfoques que actualmente se están comenzando a aplicar para fomentar, potenciar e impulsar la innovación en el sector público, inclusive más allá de sus propios límites y fronteras institucionales. 
4. INNOVACIÓN ABIERTA, CROWDSOURCING Y PENSAMIENTO DE Diseño: HaCia UN NUEVO PARADIGMA DE COLABORACIÓN, CO-DISEÑO Y CO-CREACIÓN DE CÓDIGO ABIERTO PARA LAS ORGANIZACIONES DEL SECTOR PÚBLICO

Hoy en día los gobiernos y las administraciones públicas enfrentan una nueva frontera de desafíos que no dudamos en catalogar de disruptivos y que no dispone de precedentes que nos permitan valorar en propiedad el profundo cambio que trae aparejado. En un mundo golpeado por recientes crisis de diversa índole, cuyos efectos se han hecho notar en recortes fiscales y ajustes presupuestarios, en la imperiosa necesidad de hacer más con menos, en la urgente prerrogativa por aprovechar recursos y capacidades (inclusive más allá de los límites del Estado), el espacio y dimensiones de la gestión pública tal como la conocíamos hasta ahora está dando un giro radical en cuyo eje se entremezclan fenómenos de carácter político, económico, tecnológico y muy fundamentalmente, cultural.

Es un hecho comprobado (y el que aún nos neguemos a reconocerlo y actuar en correspondencia complica más el asunto) que el modelo de burocracia estatal heredado del siglo XX está totalmente desbordado por las nuevas realidades emergentes. En definitiva, no es posible gestionar y resolver la complejidad de los problemas públicos en el siglo XXI con una infraestructura estatal (institucional, organizativa y de gestión) que se muestra totalmente anacrónica, desfasada, ajena y distante, y principalmente disfuncional en contraste a las propias características que presenta su reflejo en el espejo de la sociedad, donde fluyen nuevas fuerzas vivas, nuevos espacios de articulación, una nueva cultura que sobre la base del paradigma digital y de las redes, promueve la colaboración, la creación conjunta, la innovación social desde, para y a través de los propios ciudadanos (RamírezAlujas, 2010).

Recientemente, Hamel y Labarre planteaban la inconveniencia de seguir aferrados a modelos organizativos y de gestión ligados a lo que denominan "Gestión 1.0”, que interpretan como una densa matriz de prácticas burocráticas que fueron inventadas para minimizar los desvíos del plan maximizando la adhesión a la estrategia, que en el fondo pondera excesivamente los puntos de vista de ejecutivos de alto rango, subestima el pensamiento no convencional, desalienta la plena transparencia, disuade la iniciativa, frustra la experimentación y promueve 
una reverencia completamente injustificada por el modelo precedente, desaprovechando los talentos de liderazgo de todos, con excepción de quienes mandan (Hamel y Labarre, 2011). El modelo de Gestión 1.0 fue armado para alentar la confiabilidad, la previsibilidad, la disciplina, el alineamiento y el control, objetivos que chocan con un mundo donde los vientos de destrucción creativa están soplando con fuerza de vendaval, donde el conocimiento rápidamente se está convirtiendo en un commodity, donde los clientes/usuarios son omnipotentes y donde el pensamiento emocional impulsa la creación de valor. De allí surge la necesidad de dar paso a un enfoque de Gestión 2.0, donde los sistemas de gestión sean reconfigurados en torno de las metas de adaptabilidad, innovación, compromiso y responsabilidad. Si ello es así en otros sectores, la transformación que se debe impulsar en el sector público es enorme pues justamente su arquitectura descansa en los pilares que hoy se ven fuertemente cuestionados y latamente erosionados. Ello nos lleva a repensar las organizaciones públicas desde la apertura, desde el hacernos cargo del desafío adaptativo (Heifetz, 1997) de reacondicionar y transformar radicalmente lo que hemos venido entendiendo por gestión pública en el actual contexto.

Este fenómeno alude a que el otrora "añejo" modelo de gestión pública puede convertirse en una parte fundamental del ecosistema social que uniría a los ciudadanos, las comunidades y las empresas no mediante la absorción de nuevas responsabilidades o la construcción de capas adicionales de burocracia, sino a través de la voluntad de abrir procesos que anteriormente permanecían cerrados y compartir espacios de trabajo conjunto, a través de la apertura de datos públicos, el uso intensivo de la innovación abierta, y la invitación a trabajar bajo modelos de co-diseño, co-creación y co-producción de servicios a partir de considerar nuevos esquemas que posibiliten aprovechar la inteligencia colectiva ${ }^{4}$ y lo que se ha venido llamando "sabiduría de la multitud" (Surowiecki, 2004).

4 Para innovar en el entorno actual se requiere apertura (Chesbrough, 2011:51). Ello supone de partida, en el ámbito de la gestión y políticas públicas, el aprovechar de manera intensiva, permanente y focalizada el capital social disponible en una comunidad mediante la idea de concebir el desarrollo como un proceso conversacional (Vignolo, Ramírez y Potocnjak, 2002) a partir del cual, de manera colaborativa, inclusiva y co-responsable, se defina la agenda y acciones a impulsar para resolver viejos y nuevos problemas que requieren de respuesta estatal pero que, en muchas ocasiones, ya sea por incapacidad o recursos limitados, no se está en condiciones de poder solucionar adecuadamente. En síntesis, aprovechar las "fuerzas vivas" de la sociedad no parece ser un camino de excepción hoy en día, más bien parece ir transformándose en la regla para el presente y futuro de la gestión de los asuntos públicos y los bienes o recursos comunes. 
Como lo plantea Nambisan (2008), la transformación del modo como el gobierno enfrenta y resuelve los actuales desafíos está más ligado a la construcción de una red de innovación basada en la colaboración que depende directamente del aprovechamiento de los recursos y capacidades de las redes externas y las comunidades para ampliar o mejorar la velocidad y los resultados de innovación, y por ende, lograr impactar positivamente en el bien común. En tal sentido y en el marco de los procesos de innovación, la colaboración basada en la red se sostendría bajo cuatro principios:

1. Metas y objetivos compartidos;

2. "Visión del mundo" compartida;

3. La creación "social" del conocimiento; y

4. Una arquitectura definida para promover y desarrollar la participación.

Además, los nuevos tipos de arreglos institucionales y las herramientas de la llamada Web 2.0 (o Web Social) han surgido para hacer más sencillo y facilitar el aprovechamiento de las diversas redes de talento creativo existentes y distribuidas en distintos sectores de la sociedad. La sociedad del conocimiento o sociedad red (Castells, 2009), se distingue por una nueva cultura digital, donde priman los modelos abiertos de información y se valora la capacidad para compartir y construir conocimiento de forma colectiva. Este nuevo entorno tecno-social, fuertemente mediado por la tecnología digital y las prácticas sociales que genera, requiere de nuevas competencias para saber gestionar el riesgo y liderar el cambio, así como para desenvolverse en espacios híbridos donde lo público y lo privado conviven y donde cada vez es más difícil controlar los flujos comunicativos. Las dinámicas propias de esta sociedad globalizada y abierta cuestiona los modelos tradicionales de autoridad y reputación y tiene consecuencias directas en todos los sectores sociales implicados en la elaboración y divulgación de conocimiento (Lara, 2011).

\section{INNOVACIÓN ABIERTA Y CROWDSOURCING APLICADO A LAS ORGANIZACIONES Y} SERVICIOS PÚBLICOS: EL CAMINO HACIA UNA INFRAESTRUCTURA DE GESTIÓN INTE-

LIGENTE, ADAPTATIVA, DISTRIBUIDA Y ABIERTA A LA SOCIEDAD

Los términos crowdsourcing e innovación abierta responden a un fenómeno fundamentalmente desarrollado en los entornos empresariales que aprovecha las redes para compartir conocimiento y generar nuevas ideas productivas, en su lado 
más cívico, la sabiduría de la multitud̄ . El concepto es fácil de comprender: parte de la premisa de que la mejor manera de buscar soluciones globales a problemas globales no es consultar a un equipo de expertos cerrado sino abrir la pregunta a un mayor colectivo de gente, afectada o no, pero sí motivada para ofrecer sus puntos de vista, ideas y aportes. Se trata de dinamizar y generar tormentas de ideas globales para problemas demasiado complejos de resolver internamente. Son entonces las multitudes, las comunidades de Internet, quienes participan de forma voluntaria con su trabajo en esa dirección. De ahí el nombre de "crowdsourcing" para diferenciarlo de "outsourcing". La empresa en lugar de deslocalizar el trabajo y delegarlo hacia afuera, dinamiza el proceso e intenta recoger los resultados de abrir sus problemas a la colectividad (crowd) o multitudes inteligentes (Lara, 2011).

\section{a) La innovación abierta en los servicios}

Según el enfoque propuesto por Henry Chesbrough (2011), la innovación en los servicios es fundamental para el futuro de las organizaciones. Al acuñar el concepto de innovación abierta, hacía referencia a la idea de que para mantener o desarrollar un determinado modelo de negocio ${ }^{6}$, la apertura se transforma en un elemento vital como modo de compartir con los demás e invitarles a participar mediante dos caminos posibles: a) desde el exterior hacia el interior (cuando hace un mayor uso de ideas y tecnologías externas a su propio modelo, lo que posibilita economías de alcance); y b) desde el interior hacia el exterior (cuando una organización permite que una parte de sus ideas y tecnologías sean usadas por otras, lo

5 El concepto original se lo debemos a James Surowiecki y su libro "The Wisdom of Crowds" (2004). Por otro lado, conviene señalar que el concepto de crowdsourcing es una contracción y neologismo de "masa" o "multitud" (crowd) y "externalización" (outsourcing), acuñado por Jeff Howe en junio de 2006 en un artículo para la revista Wired ("The Rise of Crowdsourcing"). En principio, supone el acto de externalizar las tareas vinculadas a resolver un problema complejo o generar ideas frescas, tradicionalmente realizado por empleados "dentro" de una organización, a un grupo indefinido de personas "fuera" o a la comunidad ("multitud"), a través de una convocatoria abierta. Por otro lado, el paradigma de la innovación abierta (Chesbrough, 2009), originalmente propone la colaboración, la co-creación con diferentes grupos de interés y la implicación en un esfuerzo interorganizativo y sinérgico, de otras organizaciones con misiones similares, comprometidas con el territorio o incluso con finalidades mixtas lucrativas y no lucrativas en el proceso que permita integrar el conocimiento interno y el externo.

6 Entendiendo modelo de negocio como un modo de crear valor para una empresa y de captar al menos parte de ese valor para la organización (Chesbrough, 2011:54). 
que permite desarrollar economías de escala). Mediante la transformación de los productos en plataformas que incorporan innovaciones internas y externas, y una amplia gama de servicios de valor ańadido en torno a tales plataformas, las organizaciones pueden tener un respiro frente a las incesantes presiones del mercado y la sociedad (Chesbrough, 2011: 35-36). En esta perspectiva, la innovación de servicios abiertos se constituye a partir de cuatro conceptos fundamentales (cuya validez y aplicación al sector público es totalmente pertinente) (Cuadro 5):

\section{Cuadro 5. Mapa conceptual de la innovación de servicios abiertos}

\begin{tabular}{|c|c|c|c|}
\hline $\begin{array}{l}\text { Conciba su } \\
\text { negocio como una } \\
\text { organización de } \\
\text { servicios }\end{array}$ & Co-creación & Innovación abierta & $\begin{array}{l}\text { Transformación } \\
\text { de los modelos de } \\
\text { negocio }\end{array}$ \\
\hline $\begin{array}{l}\text { Utilización de los re- } \\
\text { cursos } \\
\text { Cadena de valor de los } \\
\text { servicios } \\
\text { Personalizado frente a } \\
\text { lo estándar } \\
\text { Plataformas de pro- } \\
\text { ductos } \\
\text { Plataformas de servi- } \\
\text { cios }\end{array}$ & $\begin{array}{l}\text { Conocimiento tácito } \\
\text { del cliente } \\
\text { Puntos de experiencia } \\
\text { La ventaja del conoci- } \\
\text { miento } \\
\text { Los clientes también } \\
\text { innovan }\end{array}$ & $\begin{array}{l}\text { Las economías de es- } \\
\text { cala } \\
\text { Las economías de al- } \\
\text { cance } \\
\text { Incremento de la par- } \\
\text { ticipación } \\
\text { Integración del cono- } \\
\text { cimiento } \\
\text { Ecosistemas de em- } \\
\text { presas, organizaciones } \\
\text { e individuos de apoyo }\end{array}$ & $\begin{array}{l}\text { Coherencia de las ac- } \\
\text { tividades del modelo } \\
\text { de negocio } \\
\text { La inercia del modelo } \\
\text { de negocio } \\
\text { Nuevos modelos de } \\
\text { ingresos } \\
\text { Organización de in- } \\
\text { terfaz } \\
\text { Modelos de negocio } \\
\text { de plataforma }\end{array}$ \\
\hline
\end{tabular}

Fuente: Adaptado de Chesbrough (2011: 43-59).

En este contexto, el sector público y sus organizaciones (como prestadoras de servicios) pueden ser vistas como una plataforma para la innovación abierta o un espacio (más que un medio o una gran estructura) generador de posibilidades de construir y articular un proyecto común de sociedad. Y junto con esto, la recuperación de la res publica involucra conservar el espacio público como dominio de la participación y decisión de todos sus miembros (Ramírez-Alujas, 2002).

En última instancia, la transformación que se requiere para incorporar la innovación abierta como herramienta de trabajo en el sector público va mucho más allá del tradicional cambio de fachada (ventanillas públicas, front office) e inclusive de estructuras, funciones y procesos (back office). Se debe asumir un espacio de 
intermediación e interacción totalmente diferente al modelo clásico sobre el cual se ha construido la arquitectura burocrática pública en el último siglo (sus signos más patentes -y anacrónicos en el actual contexto- son la verticalidad, la excesiva jerarquización, etc.) y ello en un escenario donde las respuestas siempre serán momentáneas y parciales, dadas las características de fluidez y cambio del entorno en el que nos movemos.

\section{PENSAMIENTO DE DISEÑO Y CO-CREACIÓN/CO-PRODUCCIÓN DE SERVICIOS: HACIA UN NUEVO ECOSISTEMA PARA PROMOVER LA INNOVACIÓN EN EL SECTOR PÚBLICO (Y MÁS ALLÁ)}

\section{a) El pensamiento de diseño}

Un valioso enfoque alternativo que ha venido siendo utilizado para liderar procesos de cambio y gestión de la innovación en el sector público es el llamado "pensamiento de diseño". Este enfoque supone fijarse en cómo los gestores públicos piensan y actúan cuando diseñan e implementan políticas y servicios, y centra la mirada tanto en el diseño como marco de referencia (o filosofía de gestión) como en el diseńo como una práctica constitutiva del quehacer vinculado a gestionar. De manera sintética, apela a impulsar un proceso creativo que pretende resolver los retos cambiando la forma en que se enfrentan, desde una metodología basada en la empatía, la contextualización y el prototipado (como forma no convencional de resolver la complejidad implícita en la resolución de los problemas públicos).

El diseño como una filosofía de gestión tiene que ver con la capacidad de equilibrar dos ideas opuestas al mismo tiempo, usando los dilemas como una fuerza poderosa para el pensamiento abierto y libre. Al ubicarnos en el plano de pensar como un diseñador, surge un espacio que implica un equilibrio entre el análisis (la capacidad para estructurar datos y pensar de manera lógica) y la síntesis (la capacidad de integrar e interpretar las diferentes perspectivas y pensar intuitivamente). Todo ello requiere de un gestor público que como diseñador pueda dominar, combinar y articular ambas perspectivas (Cuadro 6). Así, la "actitud de diseño" es fundamental y requiere de la experimentación, de la comprensión de 
cómo los seres humanos trabajan y piensan, desafiando la tradicional ortodoxia vigente sobre estas cuestiones?

El diseño como una práctica implica la aplicación de herramientas tales como la resolución de problemas críticos, la participación de los usuarios y el pensamiento sistémico ${ }^{8}$. Visto de este modo, la aplicación del pensamiento en diseño como modelo emergente supone una nueva forma de ver el mundo, de aproximarse a las restricciones (tan frecuentes en el sector público) de una manera holística, multidisciplinaria e inspiradora. En definitiva, de pasar de "diseñar para el usuario/ciudadano" a "diseñar con él".

\section{Cuadro 6. Pensamiento de diseño: Cerrando la brecha}

\begin{tabular}{l|l}
\multicolumn{1}{c|}{ Análisis (Dividir) } & \multicolumn{1}{c}{ Síntesis (Juntar) } \\
Racional & Emocional \\
Lógico & Intuitivo \\
Deductivo & Inductivo \\
Soluciones & Paradigmas, plataformas \\
"Pensándolo a través de" & Prototipado rápido ("pensarlo mientras se hace") \\
Una sola disciplina & Múltiples disciplinas (holístico) \\
Elegancia & Impacto, valor (público), difusión \\
\hline
\end{tabular}

Fuente: Adaptado de Bason (2011:8)

7 Un excelente ejemplo del uso combinado de las herramientas de innovación abierta, pensamiento de diseño y co-creación/co-producción colaborativa (de bienes públicos) aplicada a un problema público específico (vivienda social) es el caso del Proyecto "Quinta Monroy" (2002) desarrollado por Elemental, un spin-off de la Facultad de Arquitectura de la Universidad Católica de Chile y el Programa Chile Barrio del Ministerio de Vivienda y Urbanismo. Se puede ver en línea el video con esta experiencia que ha sido reconocida como referente mundial para las políticas de vivienda social básica: http://vimeo.com/794950 Para mayor detalle: ARAVENA, 2004: 30-33.

8 También se puede describir como una metodología de resolución de problemas aplicable a cualquier ámbito de innovación que requiera un enfoque creativo, y que se basa en estos principios: a) Empatía: una observación profunda de las necesidades de los usuarios, incluyendo las emociones, b) Imaginación: la búsqueda "optimista" de soluciones, de lo deseable vs. lo posible, c) Experimentación: la visualización de posibles alternativas de solución mediante el prototipado colaborativo o la construcción de sentido visual (hacer fácil lo difícil a través de imágenes), d) Aprendizaje iterativo: la iteración del proceso de observar-crear-prototipar-validar cuantas veces sea necesario, para aprender en cada paso, hasta encontrar la mejor solución. Adaptado de:http://www.amaliorey.com/2012/02/26/mi-faq-sobre-design-thinking-post-286/ 
En contraste y como ejemplo, bajo la idea de pensamiento de diseño la unidad de innovación para el sector público del gobierno australiano (PSI) lanzó una caja de herramientas" para promover la configuración de un modelo "híbrido" aplicable a la solución de problemas públicos complejos que requieran ser abordados más allá de los tradicionales límites y fronteras de las propias organizaciones públicas y que, a la vez, permitiera el aprovechamiento del capital distribuido en amplios sectores de la sociedad (empresa, academia, etc.). Para ello, adaptó un marco de referencia sobre la base de los principios rectores que sustentarían este tipo de aproximaciones:

1. Identificar el problema: Que incluye la definición del problema a través de una lluvia de ideas, el descubrimiento de las preguntas que necesitan ser respondidas, el establecimiento de espacios de empatía con el usuario final y la comprensión integral del problema. Una parte importante de este proceso es el estudio etnográfico o la investigación contextual para observar a los usuarios finales en su propio contexto y desarrollar soluciones de acuerdo a sus necesidades;

2. Creación de plan: De manera rápida, barata y en un escenario o contexto de flexibilidad. Incluye la participación de los usuarios finales o interesados, la visualización de la solución, el descubrimiento de múltiples soluciones y apertura a nuevas miradas, y el intercambio de ideas sin prejuicios;

3. Prototipos: Incluye ideas de diseño, la co-generación de opciones de solución y propuestas seminales de estudio, consulta y colaboración;

4. Pilotaje: Esto implica probar el diseńo, utilizar narrativas acerca de la solución y la forma en que ella se integra en una organización y el rediseño, si no cumple con la satisfacción de las necesidades o la resolución del problema;

5. Implementar el cambio: Lo cual puede suponer la contratación, reestructuración o consciente de que la solución

6. Evaluación: Se trata de analizar los aspectos positivos y negativos del programa (de cambio implementado en la fase piloto) y el sustento de ese nuevo conocimiento para cotejarlo y contrastarlo con el (potencial) diseño de nuevos proyectos e iniciativas.

9 Disponible en: http://innovation.govspace.gov.au/2011/12/14/achieving-innovation-throughdesign-thinking/ 


\section{b) El enfoque de co-creación (co-diseño, co-producción)}

Para algunos autores, la clave para fomentar la innovación en el sector público dice relación con incorporar el concepto de "co-creación" (Bason, 2010) ${ }^{10}$ a la idea de crear valor para la sociedad (valor público/valor social). Ello supone la construcción de un ecosistema que implica cuatro cambios simultáneos en cómo crear nuevas soluciones (Cuadro 7). Todo ello asume cerrar la brecha entre el reconocer la importancia de la innovación (discurso) y hacer algo concreto sobre ella (prácticas).

1. Conciencia: Pasar de un proceso de innovación "por azar" hacia un enfoque consciente, ingenioso y sistemático;

2. Capacidad: Transitar desde el foco en la gestión de recursos humanos a la construcción de capacidades de innovación en todos los niveles y como eje fundamental a considerar en cuestiones de estructura (organizativa);

3. Co-creación: Desplazarse desde la ejecución de tareas y proyectos (rutinarios) a "orquestar" procesos de co-creación, generando nuevas soluciones con los ciudadanos, no "para ellos" sino "con ellos"; y

4. Coraje: Moverse desde la mera "administración" de organizaciones públicas (bajo el peso de lo operativo y rutinario) a liderar con coraje la innovación en, a través y más allá del sector público.

\section{Cuadro 7. La co-creación como clave de la innovación en el sector público}

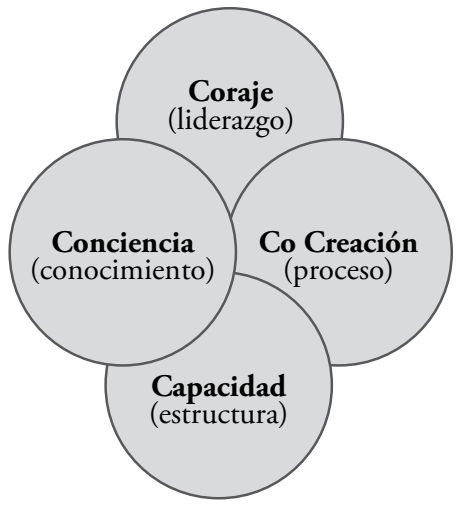

10 Se plantean las 4C para la construcción de un ecosistema de innovación en el sector público, lo que equivale (en inglés) a: a) Consciousness (awareness); b) Capacity (structure); c) Co-creation (process); $y d$ ) Courage (leadership). 
En tal sentido, Bason define la co-creación ${ }^{11}$ como un proceso sistemático de creación de nuevas soluciones "con las personas, no solo para ellas", con un alcance más amplio que permita sumar a más ciudadanos, aplicando un nuevo modelo de gestión del conocimiento (cualitativo, de primera mano) que se sustenta en un tipo diferente de proceso (impulsado por el pensamiento de diseño). Adicionalmente, afirma que sólo mediante la participación de los interesados en el diseño de servicios (co-creación) se puede hacer que los ciudadanos participen de manera más activa y habitual en la prestación de servicios (co-producción).

Para comprender mejor las bases conceptuales de este modelo, veamos en detalle a qué se refiere cada uno de sus componentes en el esfuerzo por configurar la creación de un cierto ecosistema de innovación pública radicalmente distinto al modo en que normalmente se han desarrollado estas iniciativas hasta ahora.

1. Conciencia: La construcción de un lenguaje para la innovación. Podría decirse que la innovación es una palabra difícil: puede ser interpretada de forma muy diferente según las personas y organizaciones, al final lo que podría ser muy innovador en un contexto podría considerarse de sentido común en otro. Sin embargo, las organizaciones públicas que deseen ingresar al juego de la innovación necesitan crear/ construir una conciencia acerca de la innovación como disciplina por derecho propio, y ayudar a los gestores y al personal público para que sean capaces de reconocer, aceptar y asumir las implicaciones que ello supone para ellos en este sentido;

2. Capacidad: La organización para innovar. Construir capacidad de innovación es asegurarse de que el contexto político, la estrategia, la organización, la tecnología, la cultura y toda la gente fortalezca las capacidades de una organización para innovar $-\mathrm{y}$ no al contrario-. Parafraseando a Moore (1997), se requiere alinear, fortalecer, articular y hacer compatibles las tres esferas de la creación de valor público: la gestión política, la gestión estratégica y la gestión operativa;

11 La co-creación es un requisito previo para identificar oportunidades de co-producción por varias razones. En primer lugar, le da a la burocracia una perspectiva "de afuera hacia adentro" sobre las prácticas actuales, la apertura de los ojos de los funcionarios públicos a la experiencia de sus usuarios y el fomento de la creatividad. En segundo lugar, ayuda a los funcionarios públicos para ver cómo los servicios podrían ser más valiosos y mejores para el público usuario, mientras se benefician de las propias redes y recursos de los ciudadanos. En tercer lugar, toma parte del riesgo del proceso de innovación mediante el diseño y evaluación de ideas que se basan en una necesidad genuina. Como afirma Bason: "El objetivo es capacitar a los ciudadanos para asumir más responsabilidad en la gestión de su propio caso o necesidad, creando un mayor impacto con mucho menos esfuerzo". 
3. La co-creación de un mejor servicio y los resultados. La co-creación es un enfoque para involucrar de manera mucho más directa a los ciudadanos, empresas y otros destinatarios principales de los servicios públicos en el proceso de innovación. No se centra sólo en la comprensión de los desafíos actuales, sino también en la creación de un nuevo futuro con la gente, no para ellos. Lo anterior se complementaría con otro tipo de recursos al aprovechar la creatividad y el potencial innovador de los ciudadanos, invitándoles a presentar sus propias ideas sobre cómo resolver los problemas públicos o sociales ${ }^{12}$ (mediante crowdsourcing). La co-creación no sólo asegura que frente a los desafíos de la vida real los usuarios finales de los servicios públicos sean más proactivos, sino que también guía la participación de todos los demás actores internos y externos (funcionarios públicos por ejemplo) que son críticos para la implementación de las iniciativas generadas y asegura, al menos parcialmente, un cambio de comportamiento e impacto social;

4. Coraje/Valor. Por último, independientemente de cómo sean las prácticas de innovación en el sector público (estratégica, sistemática), ella no despegará sin el liderazgo (coraje) necesario en todos los niveles de gobierno. Aquí hay cuatro perfiles aproximados sobre los tipos de liderazgo que se requieren de manera transversal en todos los niveles de gobierno para acometer el desafío de adoptar la innovación como eje de la acción pública:

- El visionario es el líder político, que debe formular la visión y establecer el nivel de ambición, mientras supera la tentación de interferir en la experimentación y en su curso de desarrollo.

- El facilitador es el administrador (gestor), que debe ser a la vez protector y campeón (Number One) de la capacidad de innovación de la organización.

- El innovador de 360 grados es el gerente de nivel medio, posiblemente el mayor escéptico a las nuevas ideas y al cambio dentro del gobierno, pero también, en el mejor de los casos, un facilitador de 360 grados de innovación.

- El ingeniero del conocimiento es la cabeza de las instituciones que prestan servicios y hacen cumplir la normas y la regulación, y

12 Dicho de otro modo, la co-creación de diferentes grupos de interés y la implicación en un esfuerzo interorganizativo y sinérgico de organizaciones y/o personas cuyos bienes "intangibles" son el conocimiento y la creatividad aplicada al desarrollo de soluciones utiliza el crowdsourcing como recurso colaborativo para resolver un problema de manera colectiva. 
que determina en última instancia cómo el sector público atiende a ciudadanos y empresas, todos los días (el funcionario de la ventanilla o que tiene contacto directo con el público usuario de servicios).

Los gobiernos y sus administraciones pueden convertirse en una plataforma para la creación de servicios y para la innovación social. Que proporciona una parte importante de los recursos, establece las normas y actúa como mediador de las disputas, pero que al mismo tiempo permite a los ciudadanos, a las empresas y a las organizaciones sociales y sin fines de lucro comprometer sus esfuerzos con las tareas más complejas y trascendentales. Esto está conduciendo a un cambio radical en la división del trabajo en la sociedad, en cómo se crea valor público y se superan, de manera conjunta y cohesionada, los efectos de la crisis que aún persiste en gran parte del planeta.

Finalmente, la apertura de la práctica de la innovación colaborativa vía co-creación, co-diseño o co-producción para, con y a través del usuario final (en otras palabras, involucrando y comprometiendo al ciudadano), no solo profundiza los vínculos entre la organización y éstos sino que presenta múltiples externalidades positivas que van de la mano con mayores niveles de co-responsabilidad y de reconfiguración de los espacios de confianza sobre los que se sustenta la acción pública y la relación entre gobernantes y gobernados.

Así y considerando el actual momento histórico, el impulsar el compromiso con los ciudadanos hace referencia a menudo a los mecanismos para fomentar la rendición de cuentas y, en última instancia, a propender a la mejora de la calidad de las políticas y servicios públicos. Sin embargo, cuando se trata de participación ciudadana, dar voz u opinión a los ciudadanos sobre determinados asuntos que les afectan (ya sea por medio de referéndums, cabildos abiertos, plebiscitos u otros dispositivos), es sólo una parte de la ecuación y, a nuestro entender, insuficiente para aprovechar todo el potencial disponible en el tejido orgánico de la sociedad civil. Generalmente, se pasa por alto el proceso de cambio institucional que debe allanar el camino y que, en última instancia, permitiría a los gobiernos responder de manera más efectiva y transversal a los ciudadanos. 
Por otra parte, los beneficios asociados al uso intensivo de una matriz participativa -como mejoras en la provisión, mejor focalización o innovación en los servicios públicos- sólo se logran cuando los actores son capaces y están dispuestos a hacer frente a las innovaciones de carácter participativo, tanto a un lado de la ventanilla (back-office, funcionarios) como al otro (front-office y ciudadanos). La implementación exitosa de las iniciativas de gobierno abierto implican una serie de procesos que son a menudo ignorados, como la creación de marcos institucionales y la elaboración de diseños adecuados de participación. Si a ello añadimos la potencialidad del uso de las TIC, podemos constatar que ellas pueden desempeñar un papel clave como medio para promover una mayor transparencia y apertura, más participación y ampliar los espacios para la colaboración y más allá.

5. El FUturo de la gestión pública y los SERVicios públicos 2.0: MÁs ALlÁ de LA INNOVACióN. La gOBERNANZa COLABORATIVA

En un reciente estudio del World Economic Forum (2011), se plantea que los principales gobiernos y Estados del mundo se están transformando a sí mismos en organizaciones planas, ágiles, simplificadas y tecnológicamente habilitadas (FAST en la sigla original en inglés). Los Estados FAST desarrollan servicios públicos innovadores, encuentran respuestas efectivas a las necesidades de los ciudadanos, cuidan de los escasos recursos naturales que poseen y crean nuevo valor público. FAST no significa necesariamente rápido, aunque el plazo para muchas de las decisiones pueda reducirse con la ayuda de las plataformas para la colaboración, ni tampoco significa ignorar los valores que sustentan al Estado en términos del mérito, equidad, equilibrio de poderes, responsabilidad y jurisdicción (WEF, 2011:12). A continuación se presenta una breve síntesis sobre los principales puntos que involucra esta mirada: 


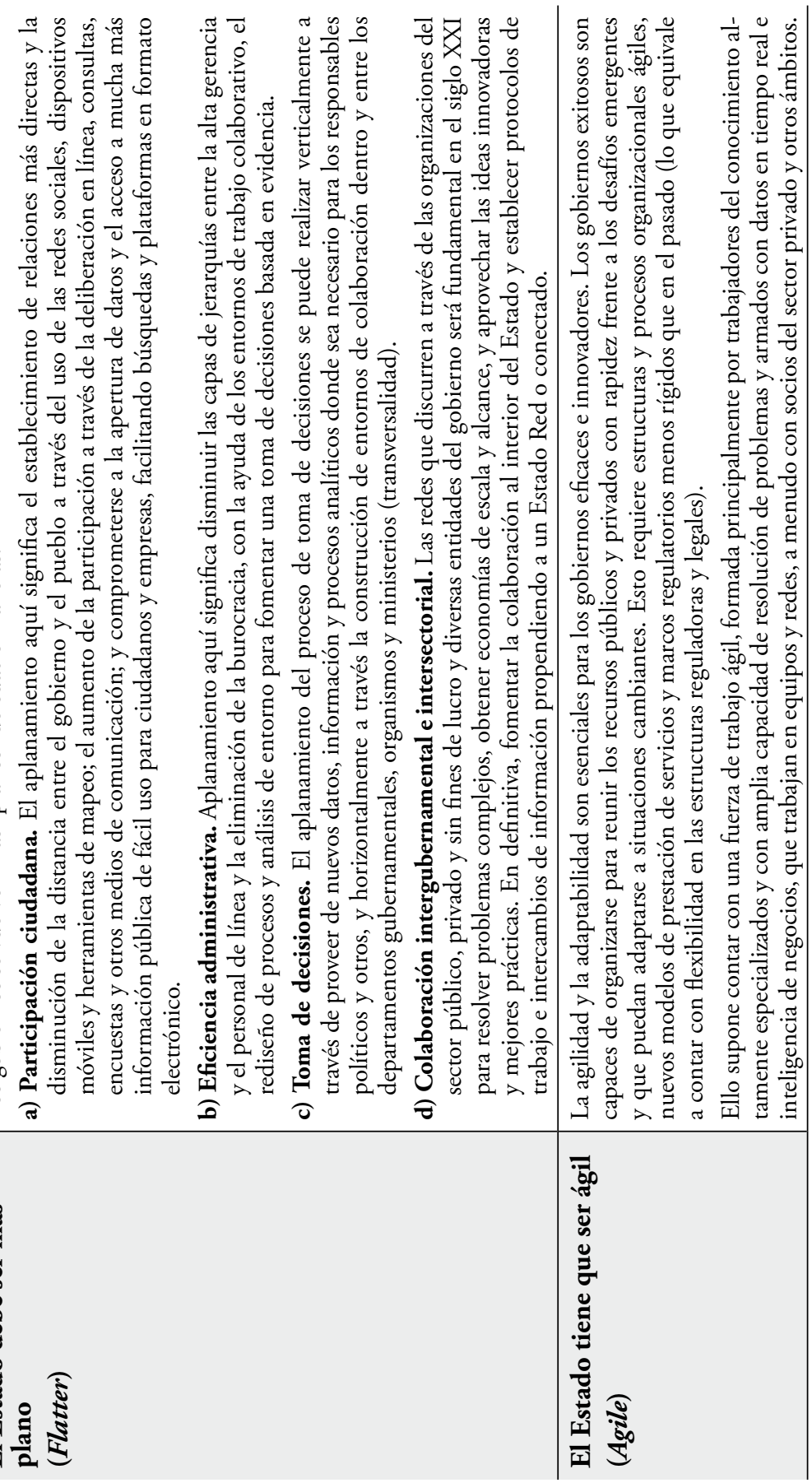




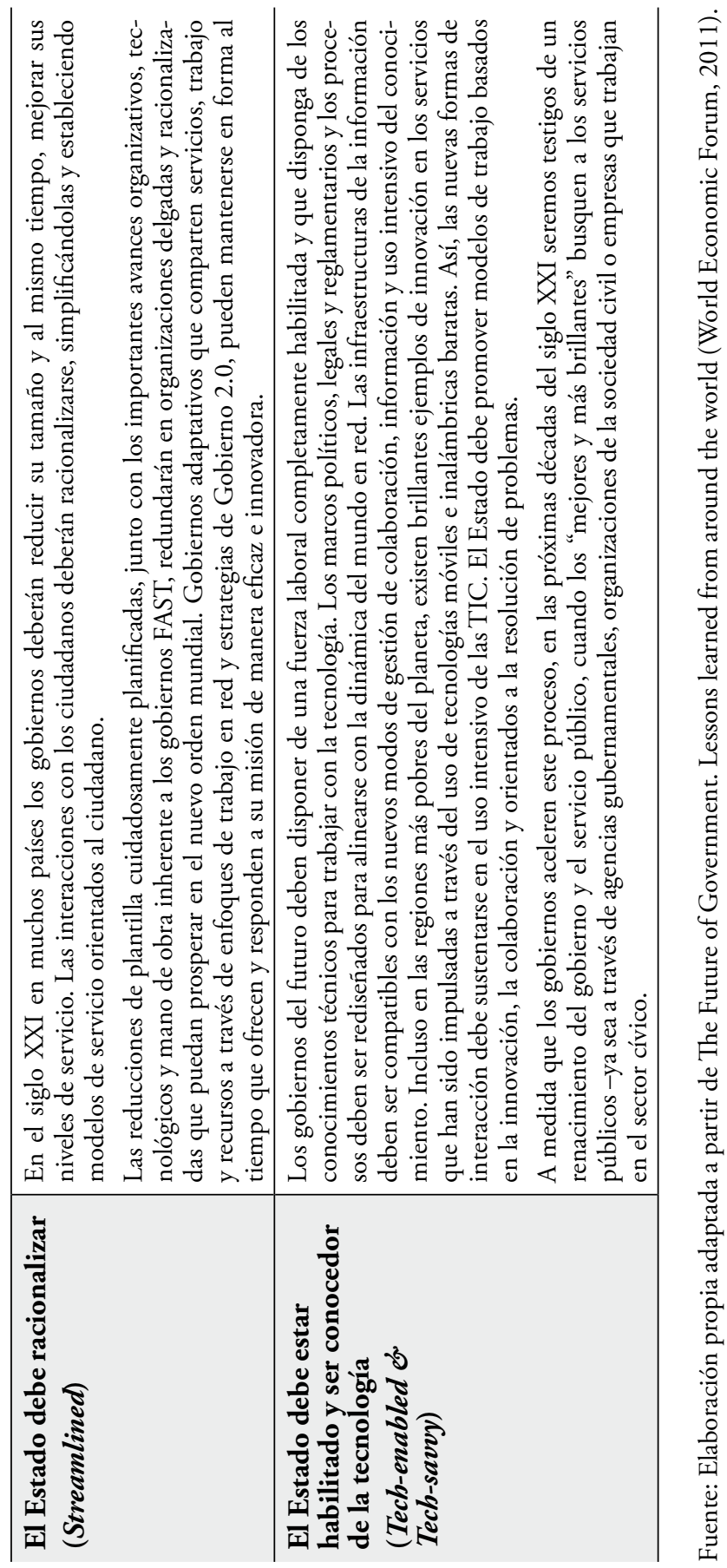


En definitiva, se trata de propender a un modelo emergente de organización pública que se fundamente en estructuras más planas y horizontales basadas en el trabajo en red (y sin la tradicional jerarquización excesiva de las burocracias públicas), mayor flexibilidad y agilidad al momento de tomar e implementar decisiones sobre la base del conjunto de nodos presentes en la red, reduciendo el tamaño y adelgazando estructuras obsoletas (y procesos) que permitan evitar la duplicación de esfuerzos y facilitar el acceder a conocimiento y recursos allí donde se requiera; y habilitadas tecnológicamente para aprovechar las múltiples opciones y posibilidades que se disponen para robustecer y consolidar un modelo más relacional de acción pública.

En síntesis, cuando hablamos de organizaciones públicas abiertas hacemos referencia expresa a la aplicación del concepto de innovación abierta o colaborativa, un modelo cuyo énfasis está en posibilitar el uso de recursos y la creatividad de redes externas y de la comunidad para amplificar el alcance, velocidad, calidad y adecuación de los esfuerzos por entregar mejores servicios (Nambisan, 2008), lo que permite contar con una diversidad de potenciales activos de innovación (individuales o colectivos) para descubrir, desarrollar e implementar ideas dentro y más allá de las fronteras organizativas del sector público (Eggers y Singh, 2009). Ello, como hemos visto, se conecta directamente con la idea de un gobierno en red.

Además, supone que los usuarios de productos y servicios (públicos) están cada vez más preparados y dispuestos a aportar en los procesos de innovación (Von Hippel, 2005), se trata de un flujo abierto de ideas que potencien la creación de valor público desde dentro hacia fuera y viceversa (Chesbrough, 2009), apertura que permite la entrada a una diversidad de actores más allá de las jerarquías y de las fronteras organizativas, y que se ajusta a desarrollar espacios para el co-diseño y la co-producción de servicios, ya no para los ciudadanos sino con ellos (Bommert, 2010; Bason, 2010). 


\section{Conclusiones}

$\mathrm{Al}$ observar desde una mirada más cultural y desde una interpretación donde se parte de que la construcción de realidad radica en el lenguaje, las emociones y el espacio conversacional, es posible distinguir la innovación como el surgimiento de "una red de conversaciones que entrelaza relaciones y operaciones que ocurren en dominios disjuntos dando origen a un nuevo dominio relacional y operacional que resulta sorprendente y deseable a la vez" (Maturana y Dávila, 2008). En este contexto, la innovación no es en sí y nos acerca a una visión mucho más radical de la que se ha venido debatiendo en su necesaria aplicación al espacio del gobierno y sus administraciones públicas. Ello se acerca (en parte) a los principios enarbolados por el Manifiesto Cluetrain (2001), donde se establecía que, a fin de cuentas, todo son conversaciones y de allí el poder transformador del lenguaje como herramienta fundamental para la construcción de "nuevas realidades". De hecho y como ejemplo de este profundo giro epistemológico, comienza a hablarse sin complejos de "narrativas de innovación"13 (Borins, 2010), "pensamiento de diseño aplicado a la gestión y políticas públicas” (Barzelay y Thompson, 2011, 2009) y creatividad.

Las organizaciones e instituciones públicas normalmente pueden beneficiarse al desarrollar espacios de colaboración, coordinación y cooperación en todos los niveles (transversalidad) y favorecer la creación de redes inter e intra-organizacionales (lo que en el actual contexto ayudaría de manera directa en los esfuerzos por generar plataformas para llevar adelante la llamada interoperabilidad entre servicios públicos que, más allá de las dificultades técnicas y tecnológicas que pueden existir, obedecen a problemas de carácter cultural, organizativo y muchas veces, de naturaleza política). Y ello tampoco se agota allí: hoy más que nunca antes es posible que en este camino el ciudadano no sea un mero espectador del proceso ni usuario final de sus resultados. Como hemos visto, el tránsito hacia espacios de co-diseño, co-creación, co-producción y colaboración permanente mediante estrategias de crowdsourcing (o mejor dicho citizensourcing) permite rescatar las

13 El terreno de la innovación y las reformas en el sector público es a menudo un espacio de pugnas (a veces insoslayables) sobre conceptos y creencias. De allí que no sea trivial que muchos de los recientes estudios sobre la temática se orienten a la necesidad de construir narrativas (Borins, 2010), generar significados y construir prácticas con fuerte sentido de pertenencia y desarrollo de espíritu de trabajo. 
mejores ideas disponibles en la sociedad al mismo tiempo que permite resignificar el valor cívico de contribuir a la producción social de bienes y servicios públicos (bajo la emergente mirada de los "commons", procomún o bienes comunes ${ }^{14}$ ).

Esto no es ficción. Hoy en día, diversas administraciones públicas en diferentes lugares del mundo están impulsando (y ensayando) nuevas estrategias para cristalizar la retórica de la innovación en un sedimento de prácticas concretas que van de la mano con refrescantes aproximaciones sobre el qué y el cómo innovar en la esfera de lo público, y mucho más allá de lo meramente estatal. Ello, de manera breve, puede sintetizarse en iniciativas que aluden a:

- Encontrar formas en que se puedan facilitar nuevas vías de colaboración intersectorial, a fin de estimular estrategias más innovadoras de desarrollo, distribución y entrega de servicios y políticas públicas;

- Abrazar el emergente concepto de un gobierno abierto, promoviendo el acceso activo de las personas a los datos públicos para desarrollar nuevas aplicaciones y prestaciones basadas en su uso y re-utilización, generando a menudo niveles de impacto social que no habían sido ni previstos ni esperados por los gobiernos y sus aparatos administrativos;

- Usando enfoques basados en la idea "Wiki" a través de la inteligencia colectiva en los procesos de mejora de los programas públicos y en la redacción de la normativas, regulaciones y legislación (como ha sido el reciente caso de Islandia y su proceso consultivo/participativo para el rediseño de su Constitución Política);

- La experimentación de nuevas formas de democracia deliberativa, ya sea en línea o en persona;

- Empoderar a los ciudadanos a través de la "co-gestión", "co-diseño" y/o "co-producción" de los servicios que necesitan para vivir una vida plena, en lugar de ser tratados como receptores (finales y pasivos) de los beneficios que desarrolla y otorga el gobierno (y en los que hasta hace poco tenían poca o nula influencia directa);

- Explorando nuevas formas para persuadir y estimular en los ciudadanos actitudes individuales que puedan acoger comportamientos pro-bien

14 Modelo de gobernanza del bien común: La manera de producir y gestionar en comunidad bienes y recursos que generan beneficio colectivo, tangibles e intangibles, que nos pertenecen a todos, o bien, que no pertenecen a nadie. Un posible catálogo del procomún incluiría los bienes naturales, científico-tecnológicos y culturales sociales. 
común en lugar de intervenir (de la manera clásica) a través de mayor regulación, fiscalización y/o impuestos;

- Servir de catalizador en la creación de fondos adicionales desde el sector privado para generar impacto social y beneficio público (lo que hoy llamamos crowdfunding), y

- Mejorar los mecanismos de auditoría y medición de todo el retorno social, ambiental y cívico derivado de la inversión pública en servicios, infraestructura y más allá.

En la actualidad, gran parte de estas nuevas formas de gestionar lo público se cristalizan en torno a la idea de gobierno abierto (Ramírez-Alujas, 2010, 2011). Los orígenes de la actual concepción del término gobierno abierto provendría de la confluencia de tres movimientos distintos que, por canales diversos, le darían sustento a los planteamientos que hemos presentado:

- “El derecho a saber" [Ver]: Que aglutina todos los avances impulsados por los movimientos ligados al derecho de acceso a la información pública, a la transparencia y rendición de cuentas, y cuyas raíces (para el caso norteamericano) pueden ser encontradas en el ideario generado por algunos periodistas a partir de la década de los ańos 50 del siglo XX y del apoyo de congresistas de esa época (como es el caso de John E. Moss Jr.). Vagamente puede encontrarse en los ideales de los padres y fundadores de la democracia americana;

- “Código Abierto" (Software Libre/Open Source) [Usar]: Articula y relaciona los diferentes movimientos que abogan por la existencia de software libre y plataformas abiertas, sobre la base de contenidos en código abierto y de libre acceso en materia de permisos, usos y reutilización de datos e información. Las raíces de este movimiento van de la mano con la aparición y desarrollo de los (mal llamados) "piratas informáticos" o hackers; con las comunidades que trabajan bajo una filosofía "abierta” (como Linux o el trabajo colaborativo que es visible en Wikipedia); y 
- “Innovación Abierta / Innovación desde los usuarios" [Hacer]: Que dice relación con la captura, facilitación e incorporación activa de las personas en los procesos de innovación y en los resultados generados a partir de ella. En cierto modo, esta vertiente se vincula a los trabajos desarrollados por Henry Chesbrough y Eric Von Hippel, aun cuando de alguna forma recogen otras fuentes de inspiración que contribuyen a darle un carácter más sustantivo y práctico desde una mirada enfocada hacia los asuntos públicos en el plano de la participación y colaboración.

De este modo, podríamos triangular que en el núcleo del concepto de gobierno abierto se entrecruza el derecho a saber ( $\mathrm{y}$ acceder a la información en manos del gobierno y administraciones y sacar provecho de la apertura de datos públicos) con el uso de fuentes, códigos y software abierto más el desarrollo de procesos de innovación abierta y orientada por, para, a través y con el ciudadano. Es decir: ver, usar y hacer.

Tal y como está sucediendo en otras esferas de desarrollo económico y social, los diseños y arquitecturas organizacionales configurados sobre la base de las ideas del siglo XX se muestran totalmente desbordados y han agotado su validez como para dar respuesta a las nuevas realidades en las que nos encontramos hoy en día. Definitivamente la era industrial (o post-industrial, si se prefiere) cuyos parámetros eran adecuados para un contexto de certidumbre, orden y control, ha dado paso de manera progresiva a la era digital (en un entorno de sociedad y Estado en red), un proceso de transición en el que los modelos de organización y gestión construidos sobre los pilares del paradigma de la era industrial está agotado en todas las instituciones que conocemos (Tapscott y Williams, 2011). De allí que sea relevante -sobre todo para instituciones y organizaciones del sector público- tratar de comprender las vías a través de las cuales los nuevos enfoques van encontrando un terreno fértil en el debate sobre la aplicación del concepto de innovación en la gestión pública y sus particularidades. Ese es el reto y al mismo tiempo, la oportunidad para comprender que la innovación ya no es una opción. Es un imperativo de carácter sistémico para la sobrevivencia de nuestra especie y el sustento de base que permitirá promover una mejor calidad de vida y mayor bienestar colectivo, 
para, con y a través de todos. Por ello, en estos tiempos agitados y confusos, la innovación que se promueva desde el sector público tiene que ser abierta, distribuida, colaborativa, horizontal, redárquica, democrática. Nos jugamos nuestro presente y futuro en este escenario, solo nos queda ponernos a trabajar y sumar un esfuerzo colectivo, compartido y comprometido a ello.

\section{REFERENCIAS BibLIOGRÁFICAS}

Altshuler, Alan; Behn, Robert (editores) (1997). Innovation in American Government: Challenges, Opportunities, and Dilemmas. USA: Brookings Institution Press.

Aravena, Alejandro; Montero, Alfonso; Cortese, Tomás; De la Cerda, Emilio; Iacobelli, Andrés. (2004). "Quinta Monroy”. ARQ (Santiago) No 57, pp. 30-33.

Barzelay, Michael; Thompson, Fred (2010). "Back to the Future: Making Public Administration a Design Science”. Public Administration Review, Vol. 70, No 1, pp. 295-297.

Barzelay, Michael; Thompson, Fred (2009). "All Aboard? Evidence-Based Management and the Future of Management Scholarship". International Public Management Journal Vol. 12, No 3, pp. 289-309.

Bason, Christian (2010). Leading public sector innovation: Co-creating for a better society. USA: Policy Press.

Bessant, J.; Hughes, T.; Richards, S. (2010). Beyond Light Bulbs and Pipelines: Leading and Nurturing Innovation in the Public Sector. UK: National School of Government.

Benkler, Y. (2006). The Wealth of Networks: How Social Production Transforms Markets and Freedom New Haven: Yale University Press.

Batorski, M; Hadden, D. (2010). Embracing Government 2.0: Leading transformative change in the public sector. USA: Grant Thornton Report.

Department of Economic and Social Affairs (2006). "Innovations in Governance and Public Administration: Replicating What Works". New York: United Nations.

Bloch, Carter (2010). Towards a conceptual framework for measuring public sector innovation. Oslo: DAMVAD.

Bommert, Ben (2010). "Collaborative innovation in the public sector". International Public Management Review, Vol. 11, No 1, pp. 15-33.

Borins, Sandford (2010). Innovation as Narrative. USA: Harvard Kennedy School. 
Borins, Sandford (2006). The Challenge of Innovating in Government. USA: IBM Center for the Business of Government.

Castells, Manuel (2009). Comunicación y Poder. Madrid: Alianza Editorial.

Chesbrough, Henry (2011). Innovación de servicios abiertos. Barcelona: Plataforma Editorial.

Chesbrough, Henry (2009). Innovación abierta: nuevos imperativos para la creación y el aprovechamiento de la tecnología. Madrid: Plataforma Editorial.

Consejo Nacional de Innovación para la Competitividad (2010). Agenda de innovación y competitividad 2010 - 2020. Santiago: CNIC.

Cornella, Alfons; Flores, Antonio (2007). La alquimia de la innovación (Reloaded). Barcelona: Ediciones Deusto.

Considine, Mark; Lewis, Jenny M. (2007). "Innovation and Innovators Inside Government: From Institutions to Networks". Governance. Vol. 20, No 4, pp. 581-607.

Eggers, William D.; Goldsmith, Stephen (2004). Governing by network the new shape of the public. USA: Brookings Institution Press.

Eggers, William; Singh, Shalabh (2009). The Public Innovators' Playbook: Nurturing bold ideas in government, USA: Deloitte Research y Ash Institute for Democratic Governance and Innovation.

Eggers, William; Campbell III, Robert; Dovey Fishman, Tiffany (2011). Letting Go of the Status Quo. A Play book for Transforming State Government. USA: Deloitte Research.

EOI (2011). "INprendedores. Experiencias y reflexiones sobre el arte del intraemprendizaje dentro de las organizaciones”. Madrid: Fundación Telefónica y EOI.

Hamel, Gary; Labarre, Polly (25 de abril de 2011). "El salto a la Gestión 2.0". Wall Street Journal, disponible en http://online.wsj.com/article/SB130350709233309467.html?mod=wsj_ share_tweet\#printMode

Heifetz, Ronald (1997). Liderazgo sin respuestas fáciles. Propuestas para un nuevo diálogo social en tiempos dificiles. Barcelona: Editorial Paidós.

Hilgers, Dennis; Piller, Frank (2011). "A Government 2.0: Fostering Public Sector Rethinking by Open Innovation". Innovation Management eJournal, disponible en http://www.innovationmanagement.se/wp-content/uploads/2011/02/A-Government-2.0-Fostering-PublicSector-Rethinking-by-Open-Innovation.pdf

Kohli, Jitinder; Mulgan, Geoff (2010). Capital Ideas: How to Generate Innovation in the Public Sector. USA: The Young Foundation. 
Lara, Tíscar (2011). Wikis para la gestión del conocimiento. Disponible en: http://tiscar.com/wiki/ index.php/Gestion-Conocimiento Consulta: 13-02-2012.

Lewis, Jenny (2010). "La innovación dentro del gobierno: análisis de la importancia de las redes de trabajo". PUBLIC No 21. Disponible en: http://www.esade.edu/public/modules.php?nam $\mathrm{e}=$ news \&idnew $=619 \&$ idissue $=56$

Maddock, S., (2009) Change you can believe in: The Leadership of Innovation. UK: The National School for Government.

Moore, Mark; Hartley, Jean (2010). Innovations in governance, in The New Public Governance? Londres: Routledge.

Moore, Mark; Sparrow, Malcolm; Spelman, William (1997). "Innovation in Policing: From production lines to jobs shops", en Altshuler, A.; Behn, R. (editores), Innovation in American Government. USA: The Brookings Institution Press.

Mulgan, Geoff (2009). The Art of Public Strategy. Mobilizing Power and Knowledge for the Common Good. UK: Oxford University Press.

Nambisan, Satish (2008). Transforming Government through Collaborative Innovation. USA: IBM Center for the Business of Government.

National Audit Office (2009). Innovation across central government. Report by the Comptroller and Auditor General, HC 12 Session 2008-2009. UK: NAO.

OECD (2009). Measuring Entrepreneurship. A Collection of Indicators. París: Eurostat Entrepreneurship Indicators Programme.

OECD (2010). Measuring innovation: A new perspective. París: OECD.

Osborne, David; Plastrik, Peter (1997). Banishing bureaucracy: the five strategies for reinventing government. USA: Reading, Mass., Addison Wesley Pub. Co.

Osborne, Stephen; Brown, Kerry (2005). Managing change and innovation in public service organizations. UK: Routledge.

Pollitt, C. (2008). "La Innovación en el Sector Público". Discurso de Apertura de la Conferencia Anual del Grupo Europeo de Administración Pública. Holanda: Erasmus Universiteit Rótterdam.

Porter, Michael; Kramer, Mark (2011). "Creating Shared Value”. Harvard Business Review, Jan-Feb.

Potts, Jason (2009). "The innovation deficit in public services: The curious problem of too much efficiency and not enough waste and failure". Innovation: management, policy \& practice, Vol. 11, No 1, pp. 34-43. 
Ramírez-Alujas, Álvaro V. (2011). "Gobierno abierto y modernización de la gestión pública: tendencias actuales y el (inevitable) camino que viene. Reflexiones seminales.” Revista Enfoques, Vol. IX, No 15, pp. 99-125.

Ramírez-Alujas, Álvaro (2011). "Sobre la aplicación y desarrollo del concepto de innovación en el sector público: Estado del arte, alcances y perspectivas”. Revista Circunstancia del IUIOG, Año IX - No 26.

Ramírez-Alujas, Álvaro (2010). “Innovación en la Gestión Pública y Open Government (Gobierno Abierto): Una vieja nueva idea”. Revista Buen Gobierno, No 9.

Ramírez-Alujas, Á.; Vignolo Friz, C.; Potocnjak Cabrera, C. (2003). "El Desarrollo como un Proceso Conversacional de Construcción de Capital Social: Marco Teórico, Una Propuesta Sociotecnológica y Un Caso de Aplicación en la Región de Aysén”. Revista Ingeniería de Sistemas, Vol. XVII, № 1.

Ramírez-Alujas, Álvaro V. (2002). “Des-encadenando la innovación en la gestión pública: la modernización del Estado como fenómeno conversacional”. Actas del VII Congreso CLAD. Portugal, Lisboa.

Shirky, Clay (2008). Here Comes Everybody. The power of organizing without organizations. New York: Penguin Press.

Surowiecki, James (2004). The Wisdom of Crowds: Why the Many Are Smarter Than the Few and How Collective Wisdom Shapes Business, Economies, Societies and Nations. USA: Random House.

Tapscott, D.; Williams, A. (2011). Macrowikinomics. Nuevas fórmulas para impulsar la economía mundial. Barcelona: Paidós.

Verhoest, Koen; Verschuere, Bram; Bouckaert, Geert (2007). "Pressure, Legitimacy, and InnovativeBehavior by PublicOrganizations”. Governance, Vol. 20, No 3, pp. 469-497.

Von Hippel (2005). Democratizing Innovation. Cambridge, MA: MIT Press.

Windrum, Paul; Koch, Per (2008). Innovation in Public Sector Services. Entrepreneurship, Creativity and Management. UK: Edward Elgar, Cheltenham.

World Economic Forum (2011). The Future of Government: Lessons Learned from around the World. Disponible en http://www3.weforum.org/docs/EU11/WEF_EU11_FutureofGovernment_Report.pdf

Recibido: 25 marzo 2012 / Aprobado: 15 mayo 2012 